\title{
Role of tumor associated macrophages in tumor angiogenesis and lymphangiogenesis
}

\section{Vladimir Riabov ${ }^{1,2+}$, Alexandru Gudima ${ }^{1,3+}$, Nan Wang ${ }^{1}$, Amanda Mickley ${ }^{1,3}$, Alexander Orekhov ${ }^{2}$ and Julia Kzhyshkowska ${ }^{1,2,3 *}$}

${ }^{1}$ Department of Dermatology, University Medical Center and Medical Faculty Mannheim, Ruprecht-Karls University of Heidelberg, Mannheim, Germany

2 Department of Nanopathology, Institute of General Pathology and Pathophysiology, Russian Academy of Medical Sciences, Moscow, Russia

${ }^{3}$ Department of Innate Immunity and Tolerance, University Medical Center and Medical Faculty Mannheim, Institute of Transfusion Medicine and Immunology,

Ruprecht-Karls University of Heidelberg, Mannheim, Germany

\section{Edited by:}

Vijaya Iragavarapu-Charyulu, Florida

Atlantic University, USA

Reviewed by:

Andrea Foskett, Texas A\&M Health

Science Center, USA

Jincai Luo, The University of Tokyo, Japan

*Correspondence:

Julia Kzhyshkowska, Department of Innate Immunity and Tolerance,

Medical Faculty Mannheim, Institute of Transfusion Medicine and

Immunology, Heidelberg University,

German Red Cross Blood Service

Baden-Württemberg - Hessen,

Theodor-Kutzer Ufer 1-3, D-68167

Mannheim, Germany

e-mail: julia.kzhyshkowska@

medma.uni-heidelberg.de

tThese authors have contributed

equally to this work.
Tumor angiogenesis is an essential process for supplying rapidly growing malignant tissues with essential nutrients and oxygen. An angiogenic switch allows tumor cells to survive and grow, and provides them access to vasculature resulting in metastatic disease. Monocyte-derived macrophages recruited and reprogrammed by tumor cells serve as a major source of angiogenic factors boosting the angiogenic switch. Tumor endothelium releases angiopoietin-2 and further facilitates recruitment of TIE2 receptor expressing monocytes (TEM) into tumor sites. Tumor-associated macrophages (TAM) sense hypoxia in avascular areas of tumors, and react by production of angiogenic factors such as VEGFA. VEGFA stimulates chemotaxis of endothelial cells (EC) and macrophages. In some tumors, TAM appeared to be a major source of MMP9. Elevated expression of MMP9 by TAM mediates extracellular matrix (ECM) degradation and the release of bioactive VEGFA. Other angiogenic factors released by TAM include basic fibroblast growth factor (bFGF), thymidine phosphorylase (TP), urokinase-type plasminogen activator (UPA), and adrenomedullin (ADM). The same factors used by macrophages for the induction of angiogenesis [like vascular endothelial growth factor A (VEGF-A) and MMP9] support lymphangiogenesis. TAM can express LYVE-1, one of the established markers of lymphatic endothelium. TAM support tumor lymphangiogenesis not only by secretion of pro-lymphangiogenic factors but also by trans-differentiation into lymphatic EC. New pro-angiogenic factor YKL-40 belongs to a family of mammalian chitinase-like proteins (CLP) that act as cytokines or growth factors. Human CLP family comprises YKL-40, YKL-39, and SI-CLP. Production of all three CLP in macrophages is antagonistically regulated by cytokines. It was recently established that YKL-40 induces angiogenesis in vitro and in animal tumor models. YKL-40-neutralizing monoclonal antibody blocks tumor angiogenesis and progression. The role of YKL-39 and SI-CLP in tumor angiogenesis and lymphangiogenesis remains to be investigated.

Keywords: tumor-associated macrophages, TIE2 receptor, VEGF, LYVE-1, stabilin-1, chitinase-like protein

\section{INTRODUCTION}

Tumor-associated macrophages (TAM) are key cells controlling tumor angiogenesis. TAM originate from circulating monocytes which are recruited to the tumor site and programmed by tumorderived factors such as colony-stimulating factor-1 (CSF-1), vascular endothelial growth factor A (VEGF-A) and CC chemokine ligand 2 (CCL2) (Mantovani et al., 1992; Qian and Pollard, 2010). These and other factors in the tumor microenvironment shape the TAM phenotype and skew them toward tumor-supportive M2-polarized macrophages, although M1-polarized TAM with anti-tumor activity were also reported in several types of cancer (Forssell et al., 2007; Galarneau et al., 2007; Ong et al., 2012; Sica and Mantovani, 2012). Macrophage density correlates with poor prognosis in many types of human cancer. Tumor supporting functions of TAM including stimulation of tumor cell growth and the creation of favorable conditions for tumor cell intravasation into vessels and metastatic spread are well-described in animal models of breast cancer (Lin et al., 2006; Qian and Pollard, 2010). Numerous recent studies have demonstrated that TAM function as major producers of pro-angiogenic factors in malignant tumors. The angiogenic switch is an important step in cancer progression. The formation of new blood vessels is essential for fast growing tumor cells to be supplied with nutrients and oxygen. The angiogenic switch allows tumor cells to survive and provides them access to vasculature, which may result in the escape of malignant cells into circulation and onset of metastatic disease. Macrophages recruited and reprogrammed by tumor cells produce factors mediating the angiogenic switch (Huang et al., 2002; Lin et al., 2006; Du et al., 2008). The contribution of TAM to tumor angiogenesis was described in animal models of breast cancer, melanoma, prostate cancer, cervical cancer, and ovarian cancer (Huang et al., 2002; Egami et al., 2003; Giraudo et al., 2004; 
Lin et al., 2006; Halin et al., 2009). A positive correlation between TAM infiltration and angiogenesis was found in many human cancers including breast cancer, melanoma, pulmonary adenocarcinoma, glioma, gastric cancer, B-cell non-Hodgkin's lymphoma, mucoepidermoid carcinoma of salivary glands, and leiomyosarcoma (Leek et al., 1996; Nishie et al., 1999; Takanami et al., 1999; Vacca et al., 1999; Torisu et al., 2000; Shieh et al., 2009; Espinosa et al., 2011; Wu et al., 2012).

Clear evidence for the role of TAM in tumor angiogenesis was reported by Lin and colleagues using the polyoma virus middle T oncogene (MMTV-PyMT) spontaneous mouse model of mammary adenocarcinoma (Lin et al., 2006). Increased infiltration of the primary tumor with macrophages was associated with an angiogenic switch. In CSF-1-null mice, macrophage infiltration of the tumor site was significantly lower and accompanied by impaired development of the vasculature network. This was a direct effect of the absence of macrophages in the tumors since the restoration of macrophage numbers in the tumors of CSF1-null mice by the transgenic expression of CSF-1, specifically in the mammary epithelium, resulted in the increase of vessel density. VEGF was depleted in the stromal cells of tumors of CSF-1 null mice suggesting that this is a significant reason of impaired angiogenesis. Another in vivo study demonstrated that human breast cancer spheroids implanted into nude mice induced more pronounced vascularization if they were infiltrated with macrophages before implantation (Huang et al., 2002). In this model, macrophages contributed significantly to VEGF release by spheroids and increased the angiogenic response. Up to date, VEGF-A is the best characterized TAM-derived cytokine involved in tumor angiogenesis.

\section{VEGF PRODUCTION AND PROCESSING BY TAM}

The ability of TAM to accelerate vessel growth is mediated through the up-regulation and release of several pro-angiogenic factors. The tumor microenvironment polarizes macrophages toward M2 or a mixed M1/M2 phenotype, which is characterized by elevated expression of potent pro-angiogenic factors (Ly et al., 2010; Rolny et al., 2011). Re-polarization of the TAM phenotype toward M1 manifests in inhibition of pro-angiogenic activity and elevated expression of anti-angiogenic factors such as CXC-chemokine ligand 9 (CXCL9) and IFN- $\beta$ (Rolny et al., 2011). VEGF-A is known as a major pro-angiogenic cytokine released by TAM. Its levels correlate with TAM density in several types of human cancer (Valkovic et al., 2002; Shieh et al., 2009). In breast cancer, TAM produce VEGF-A in hypoxic avascular areas of tumors (Lewis et al., 2000). Recently, the MHCII low subset of TAM which resides in hypoxic areas of tumors was shown to be associated with a pro-angiogenic gene signature and increased VEGF-A expression (Laoui et al., 2013). The accumulation and retention of TAM in hypoxic areas of tumors seems to be specifically regulated by hypoxia-induced factor semaphorin $3 \mathrm{~A}$ which triggers macrophage recruitment through VEGFR1 (Casazza et al., 2013). In macrophages, hypoxia induces expression of hypoxia inducible factor (HIF-1 $\alpha$ and HIF- $2 \alpha$ ) transcription factors, the major master regulators of VEGF-A expression (Bingle et al., 2002; Burke et al., 2002; Imtiyaz et al., 2010; Staples et al., 2011). However, recent studies reported that HIF-1 $\alpha$ and
HIF-2 $\alpha$ may play opposing roles in tumor angiogenesis (Eubank et al., 2011; Roda et al., 2012). In a mouse melanoma model, chemical stabilization of HIF- $2 \alpha$ in TAM stimulated production of a soluble form of the VEGF receptor (sVEGFR-1) which neutralized biological activity of VEGF-A. This resulted in reduced angiogenesis and tumor growth (Roda et al., 2012). In contrast, HIF- $1 \alpha$ expression in TAM was responsible for VEGF-A production. In agreement with this study, co-culture of breast cancer spheroids with wild type or HIF- $1 \alpha$ knocked out macrophages revealed an indispensable role of macrophage-expressed HIF- $1 \alpha$ in tumor angiogenesis (Werno et al., 2010). Besides hypoxia, HIF-1-controlled VEGF-A expression can be induced by several cytokines. The production of IL1 $\beta$ by TAM is able to induce HIF$1 \alpha$ expression and VEGF-A release in tumors. It was shown that IL1 $\beta$ stimulates HIF- $1 \alpha$ production in several cancer cell lines even under normoxic conditions (Jung et al., 2003). Another common TAM-produced cytokine, transforming growth factor $\beta 1$ (TGF $\beta 1$ ), also contributes to VEGF-A expression in mouse macrophages through HIF- $1 \alpha / \beta$ - and Smad3/4-dependent mechanisms (Jeon et al., 2007). Alternatively, VEGF-A expression can be induced by tumor-released CSF-1 (M-CSF), which acts through NF- $\kappa$ B activation and, in combination with CCL2, promotes pro-angiogenic functions of macrophages (Eubank et al., 2003; Wyckoff et al., 2004). Moreover, irradiation stimulates tumor cells to produce higher levels of CSF-1 resulting in the enhanced infiltration of pro-angiogenic myeloid cells into the tumor site (Rego et al., 2013; Xu et al., 2013). Upon secretion from cells, VEGF-A associates with extracellular matrix (ECM) and its soluble form can be released by enzymatic cleavage of ECM by matrix metalloproteinases (MMPs) (Lee et al., 2005). Several studies revealed that TAM can significantly contribute to this process. In a mouse model of human ovarian cancer, TAM were found to be a major source of MMP9. Furthermore, the presence of MMP9-expressing TAM positively correlated with tumor angiogenesis, tumor growth and VEGF-A levels (Huang et al., 2002). Elevated expression of MMP9 by tumor-infiltrating inflammatory cells in a mouse pancreatic cancer model mediated the release of bioactive VEGF-A from its extracellular reservoir (Bergers et al., 2000). In a similar study using a mouse glioblastoma tumor model, MMP9-producing macrophages and TIE2+ monocytes (TEM) contributed to the release of bioactive VEGFA from its ECM-bound form. These bone marrow-derived cells were recruited into tumors by the HIF-1 target molecule CXCchemokine ligand CXCL12 (SDF-1 $\alpha$ ) released by tumor cells (Du et al., 2008). It should be noted that targeting CXCL12 and its receptor CXCR4 in mouse glioblastoma prevented HIF-1mediated recruitment of pro-angiogenic TAM and TEM, reduced vasculogenesis and abrogated tumor growth after irradiation (Kioi et al., 2010). Interestingly, a recent study demonstrated that in contrast to high-dose tumor irradiation, local low-dose gamma irradiation of pancreatic carcinomas induced TAM with an antitumor immunostimulatory phenotype. These TAM downregulated HIF-1 expression and suppressed intratumoral VEGF-A production resulting in the normalization of tumor vasculature. This study emphasizes the plasticity of the TAM phenotype and the possibility to revert their pro-angiogenic properties through dampening of VEGF-A-dependent angiogenesis (De Palma et al., 
2013; Klug et al., 2013). Altogether, most of the studies demonstrate the indispensable role of TAM in the induction of tumor angiogenesis either through the direct production of VEGF-A or modulation of its accessibility in the tumor microenvironment.

Despite the undeniable role of VEGF in tumor angiogenesis, several studies revealed that other molecular factors (presumably HIF-1-induced factors) can significantly contribute to this process (Kioi et al., 2010; Chen et al., 2012).

\section{OTHER ANGIOGENIC FACTORS RELEASED OR INTERNALIZED BY TAM}

Besides VEGF, TAM release a panel of pro-angiogenic factors which include tumor necrosis factor $\alpha(\mathrm{TNF} \alpha)$, basic fibroblast growth factor (bFGF), thymidine phosphorylase (TP), urokinasetype plasminogen activator ( $\mathrm{uPA})$, adrenomedullin (ADM), and semaphorin 4D (Sema4D) (Hildenbrand et al., 1995; Leek et al., 1998; Mantovani et al., 2007; Sierra et al., 2008; Chen et al., 2011). TP stimulates the migration of endothelial cells (EC), whereas uPA mediates ECM degradation and increases vascular invasion (Hotchkiss et al., 2003; Piao et al., 2005; Basire et al., 2006; Bijnsdorp et al., 2011). Macrophage-derived TP was associated with angiogenesis and reduced survival in human glioma and intestinal type gastric cancer (Yao et al., 2001; Kawahara et al., 2010). Elevated expression of TP is correlated with a poor prognosis in breast cancer and pancreatic cancer, and uPA expression is correlated with a poor prognosis in breast cancer (Takao et al., 1998; Toi et al., 1999; Harbeck et al., 2002). Macrophagederived IL1 $\alpha$ directly stimulated endothelial tube formation and neovascularization, as well as growth of mouse prostate tumors (Kwon et al., 2013). TAM-derived ADM was shown to induce angiogenesis and tumor growth in a mouse model of melanoma, and can potentially be implicated in human melanoma angiogenesis (Chen et al., 2011). In mouse models of breast cancer, TAM-produced Sema4D was found to be critical for tumor angiogenesis, vessel maturation, and tumor growth (Sierra et al., 2008). Sema4D induced motility of EC via the engagement of receptor plexin B1. In Sema4D KO mice, interactions between EC and pericytes (an essential process in vessel formation) were disrupted. Another macrophage-derived pro-angiogenic factor, prostaglandin $\mathrm{E} 2\left(\mathrm{PGE}_{2}\right)$, can be potentially involved in pathological angiogenesis induced in tumors by therapeutic interventions which stimulate apoptosis. It was shown that apoptotic cells activated an angiogenic program in human macrophages resulting in $\mathrm{PGE}_{2}$-mediated endothelial cell migration (Brecht et al., 2011).

Macrophages communicate with other cell types and control tissue turnover not only by the release of various factors, but also by their internalization and degradation. This clearance function is especially effective in alternatively activated macrophages (M2) (Kzhyshkowska and Krusell, 2009). Thus, the clearance of secreted protein acidic and rich in cystein (SPARC), a soluble component of ECM that inhibits angiogenesis by the modulation of expression of VEGF and MMPs (Zhang et al., 2012a), has been demonstrated by us in human alternatively activated macrophages (Kzhyshkowska et al., 2006a). Multifunctional scavenger receptor stabilin-1 is responsible for SPARC uptake and targeting for degradation in lysosomes. We and others also found in several tumor models that stabilin-1 is expressed by TAM
(Schledzewski et al., 2006; Werno et al., 2010; Algars et al., 2012; David et al., 2012), leading to the hypothesis that stabilin-1mediated clearance of SPARC can affect tumor angiogenesis. The clearance function of TAM as a mechanism of the regulation of angiogenesis is underestimated at the moment and has to be addressed experimentally.

\section{TAM INDUCE ANGIOGENIC ACTIVITY IN TUMOR CELLS}

The involvement of TAM in tumor angiogenesis is not limited to the self-production of angiogenic factors. TAM are able to release cytokines that indirectly contribute to tumor angiogenesis by the induction of a pro-angiogenic program in tumor cells. It was demonstrated that human monocytes and macrophages induced the production of the pro-angiogenic factors IL-8 and VEGF from melanoma and glioma cells during co-culture (Torisu et al., 2000; Hong et al., 2009). Elevated expression of IL-8 during co-culture with macrophages was also found in several lung cancer, osteogenic sarcoma and hepatoma cell lines (Chen et al., 2003). Up-regulation of IL-8 expression was presumably mediated by TAM-derived TNF $\alpha$ and IL $1 \alpha$, which stimulated NF- $\kappa B$ activity in tumor cells (Yao et al., 2005). Macrophage-derived $\mathrm{TNF} \alpha$ and IL- $1 \alpha$ were necessary for the release of IL- 8 and VEGF from melanoma cells (Torisu et al., 2000). In vitro M2-polarized monocyte-derived macrophages enhanced the angiogenic potential of human basal cell carcinoma cells through the induction of cyclooxygenase-2 (COX-2) expression resulting in the elevated release of VEGF and bFGF from tumor cells (Tjiu et al., 2009). Thus, tumor cells and recruited TAM cooperate in the tumor microenvironment to amplify the production of pro-angiogenic factors resulting in an angiogenic switch (Figure 1).

\section{TIE2 EXPRESSING MONOCYTES AS MAJOR INDUCERS OF TUMOR ANGIOGENESIS}

There is a growing set of evidence that specific subpopulations of TIE2 receptor expressing monocytes (TEM) in mice and humans significantly contribute to tumor angiogenesis (Lewis et al., 2007; Matsubara et al., 2013). These monocytes/macrophages are attracted into the tumors by endothelial cell (EC)-derived cytokine angiopoietin-2 (ANG-2), which interacts with its receptor TIE2 (Huang et al., 2011). In addition, TEM express chemokine receptor CXCR4 and can be attracted into tumors by CXCL12 (Welford et al., 2011). This subpopulation of macrophages is associated with vessels and is highly angiogenic acting in a paracrine manner (De Palma et al., 2005). It is not known whether TIE2 expressing monocytes are recruited into specific types of solid tumors and whether stimulation of TIE2 expression in the conventional TAM associated with blood vessels can result into development of TEM phenotype. Blood circulating TIE2 expressing monocytes are already pre-programmed to exert pro-angiogenic activity and express elevated levels of MMP9, VEGF-A, COX-2, and Wnt5a (Coffelt et al., 2010). When stimulated by EC-derived ANG-2, TEM additionally upregulate several pro-angiogenic factors including $\mathrm{TP}$ and cathepsin $\mathrm{B}$. Moreover, ANG-2 induces the expression of IL-10 and CCL17 by TEM, factors which suppress T-cell proliferation and promote the expansion of regulatory T-cells providing tumor cells with a way to escape from immune responses (Coffelt et al., 


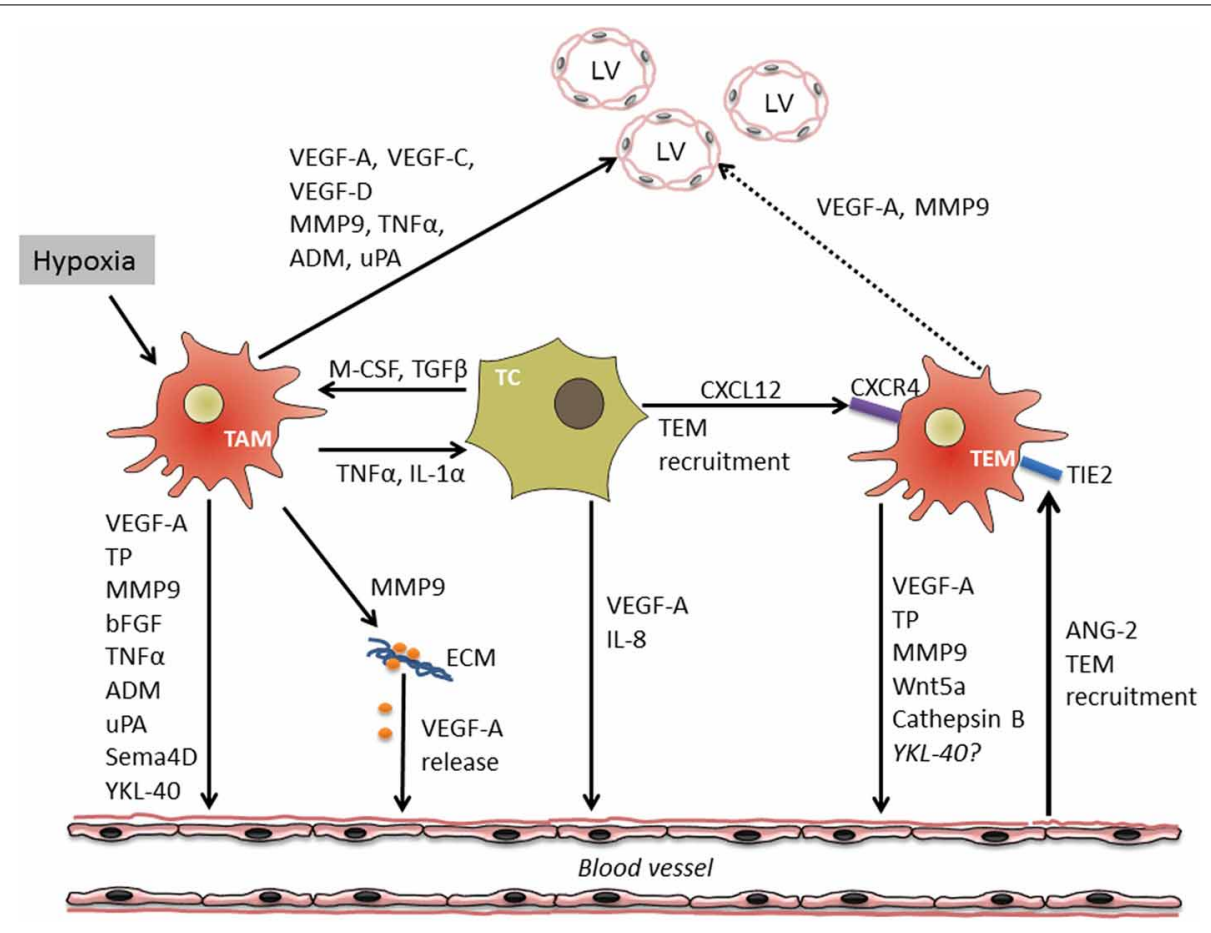

FIGURE 1 | Cross-talk between macrophages, tumor cells and endothelium during tumor angiogenesis and lymphangiogenesis. Tumor hypoxia and cytokine crosstalk between tumor cells (TC) and TAM results in the induction of a pro-angiogenic program in both cell types followed by the release of multiple soluble factors stimulating migration and proliferation of vascular endothelial cells (VEC) either directly or through the mobilization of extracellular matrix (ECM)-bound VEGF-A. In addition, TC and VEC are able to attract specific population of TIE-2 expressing monocytes (TEM) with high angiogenic potential. TAM and TEM-derived factors as well-induce growth of tumor lymphatic vessels (LV). Through the production of factors such as VEGF-A and MMP9 influencing growth of both lymphatic and vascular EC, TAM link processes of tumor angio- and lymphangiogenesis.
2011). TEM were described to cause re-growth of subcutaneous breast and lung carcinomas after local irradiation (Kozin et al., 2010). In addition, they limited the efficacy of vascular-disrupting compounds in murine mammary tumors, presumably initiating vascular repair (Welford et al., 2011). Several studies reported an important role of EC in the differentiation and functional activity of TEM. The interaction of TEM with activated EC was important for TIE2 upregulation and the establishment of a pro-angiogenic program in TEM (Mazzieri et al., 2011). A blockade of EC-derived ANG-2 in mouse MMTV-PyMT mammary cancer downregulated TIE2 expression in TEM and disrupted their association with angiogenic blood vessels. The inhibition of TIE2 expression by TEM resulted in reduced tumor angiogenesis. In another study, co-culture of primary EC with bone marrow-derived hematopoietic progenitor cells drove the differentiation of pro-angiogenic TIE2 expressing macrophages, which established tight associations with EC and supported tumor growth. The expansion of macrophage colonies was induced by EC-derived CSF-1 (He et al., 2012). Interestingly, expression profiles of TEM, resident monocytes and TIE2 expressing embryonic macrophages are related, suggesting that these myeloid populations represent developmental stages of TEM (Pucci et al., 2009). Recently, Medina and colleagues characterized a subpopulation of pro-angiogenic monocytes from human peripheral blood which were also referred to as myeloid angiogenic cells (MACs) (Medina et al., 2011). These cells had a signature of M2-polarized macrophages and expressed a panel of markers including CD163, IL-10 and macrophage scavenger receptor-1 (MSR-1). Moreover, they expressed and released a spectrum of pro-angiogenic factors such as IL-8, MMP9, and VEGF. According to the gene expression profile, MACs resembled TEM and induced endothelial tubule formation mediated mainly through IL-8 release. The role of this monocytic subpopulation in tumor angiogenesis was not described. However, their clear pro-angiogenic properties and predisposition to M2 polarization suggest a potential contribution to tumor angiogenesis once these cells are recruited to the tumor site. A summary of the complex regulation of angiogenesis by TAM is schematically presented on Figure 1.

\section{EFFECT OF TAM ON LYMPHANGIOGENESIS}

In recent years, evidence has accumulated that macrophages are not only critical regulators of angiogenesis, but also crucial participants in lymphangiogenesis, both in inflammatory settings and in tumors (Ran and Montgomery, 2012). Importantly, macrophages may simultaneously induce both angiogenesis and lymphangiogenesis by the production of VEGF-A and MMP9. These cytokines which are abundantly produced by subpopulations of TAM were shown to induce the development of both blood and lymphatic vessels. Thus, TAM-derived factors can link tumor angiogenesis and lymphangiogenesis (Scavelli et al., 2004; Coffelt et al., 2009; Gomes et al., 2013) (see Figure 1). 
Macrophages can utilize two main pathways to stimulate lymphangiogenesis: either by the direct secretion of prolymphangiogenic factors or by trans-differentiation into lymphatic EC, actively taking part in the formation of lymphatic vessels (Kerjaschki, 2005). TAM can express a major marker of lymphatic vessels, LYVE-1 (lymphatic vessel endothelial hyaluronan receptor (1), both in murine and human tumors (Schledzewski et al., 2006; Zumsteg et al., 2009). It was reported that in mouse models of pancreatic insulinoma and prostate cancer F4/80 ${ }^{+}$Lyve- $1^{+}$ TAM directly integrated into peritumoral lymphatic vessels and presumably lost their macrophage features upon this integration (Zumsteg et al., 2009). Even though not all researchers agree with the trans-differentiation hypothesis (Gordon et al., 2010), the fact that certain macrophages secrete pro-lymphangiogenic factors in certain circumstances, such as in inflammation or tumors, is undisputed. Below we review the pro-lymphangiogenic factors secreted by tumor associated macrophages (TAM), as well as the role of TAM density in evaluating tumor lymphangiogenesis.

\section{FACTORS PRODUCED BY TAM THAT REGULATE LYMPHANGIOGENESIS}

There are a few factors produced by TAM that are responsible for the induction of lymphangiogenesis, with VEGFR-3 and its ligands, VEGF-C and VEFG-D, thought to have a key role in it. Studies have shown that VEGF-C producing tumor cells significantly increase intratumoral lymphangiogenesis together with regional metastasis (Skobe et al., 2001a). Additionally, the inhibition of VEGFR-3 with receptor-specific antagonist antibodies was shown to suppress tumor lymphangiogenesis as well as regional and distant metastasis (Roberts et al., 2006). Schoppmann et al. found that TAM expressing VEGF-C, VEGF-D, and VEGFR3 substantially increased tumor lymphatic microvessel density (LVD) in cervical cancer (Schoppmann et al., 2002). In another study, they showed that TAM expressing VEGF-C increased tumor lymphangiogenesis and lymphovascular invasion in breast cancer. Moreover, a positive correlation was found between VEGF-C $^{+}$stromal cells and VEGF-C ${ }^{+}$tumor cells (Schoppmann et al., 2006). Similar findings were obtained in a study of Lewis lung carcinoma cells in which M2 macrophages displayed the ability to induce VEGF-C expression in tumor cells (Zhang et al., 2012 b). By depletion of VEGFR-3 ${ }^{+}$TAM with clodronate liposomes, Yang et al. were able to obtain a considerable reduction (>80\%) in the secretion of VEGF-C and VEGF-D in the tumor mass and also a significant reduction in LVD (Yang et al., 2011). Recently, the critical role of VEGF-C producing TAM in lymphangiogenesis and tumor dissemination was found in mantle cell lymphoma (Song et al., 2013). The description of VEGF-C expressing TAM and their prolymphangiogenic influence can also be found in a variety of other studies (Jeon et al., 2008; Moussai et al., 2011; Ding et al., 2012; Werchau et al., 2012; Wu et al., 2012).

Although VEGF-C, VEGF-D, and VEGFR-3 are mainly regarded as prolymphangiogenic factors, there are studies suggesting their role in angiogenesis. The mature forms of VEGF-C and VEFG-D possess the ability to bind to VEGFR-2, a receptor associated with angiogenesis (Joukov et al., 1997; Stacker et al., 1999; Lohela et al., 2009). Moreover, VEGF-C was shown to promote angiogenesis in vivo and to promote angiogenesis, in addition to lymphangiogenesis, in melanoma models (Cao et al., 1998; Skobe et al., 2001b). VEGFR-3 is also associated with the promotion of angiogenesis. In a study on mouse angiogenesis models, the blockage of VEGFR-3 with monoclonal antibodies was found to decrease sprouting, vascular density and endothelial cell proliferation. Additionally a blockage of VEGFR-3 in combination with the blockage of VEGFR-2 resulted in additive inhibition of angiogenesis and tumor growth (Tammela et al., 2008).

VEGF-A, a classical pro-angiogenic factor expressed by TAM, was found to be involved also in lymphangiogenesis. Apart from indirectly stimulating lymphangiogenesis by recruiting macrophages (Cursiefen et al., 2004), VEGF-A has been shown to induce proliferation and migration of VEGFR-2 expressing lymphatic endothelial cells (LEC) in vitro (Hong et al., 2004) and to induce sentinel lymph node lymphangiogenesis in a skin cancer model (Hirakawa et al., 2005). In a fibrosarcoma model, VEGFA displayed the ability to induce peritumoral lymphangiogenesis as well as contribute to lymphatic metastasis (Bjorndahl et al., 2005a). Anti-VEGF-A therapy proved to be an effective way to reduce both blood and lymphatic vascular densities in a breast cancer model. Moreover, it decreased the VEGFR-3 expression levels in LEC and reduced the incidence of regional and distant metastasis (Bjorndahl et al., 2005b; Whitehurst et al., 2007).

In addition to the expression of direct inducers of lymphangiogenesis, TAM regulate lymphangioegensis, also indirectly, by the production of enzymes, such as MMP, plasmin and urokinase plasminogen activator ( $\mathrm{uPA}$ ), that regulate matrix remodeling and growth factor activation (Allavena et al., 2008). Matrix remodeling and growth factor activation are very important processes, both in angiogenesis and lymphangiogenesis. MMP-2 and MMP-9 have been shown to have a role in governing the formation of lymphatic vessels. MMP-2 facilitates LEC migration through collagen fibers, which is otherwise affected by physical matrix constraints. Inhibition or downregulation of MMP-2 and MMP-9 reduces lymphangiogenesis, the invasive ability and tube-forming properties of LEC (Nakamura et al., 2004; Detry et al., 2012) that supports the idea that MMP-2 and MMP-9mediated lymphangiogenesis contribute their ability to promote several types of tumors. Along with MMP-1 and MMP-2, uPA was shown to have a role in lymphatic progression of oral tongue squamous cell carcinoma (Zhang et al., 2011a). Plasmin has been reported to activate the lymphangiogenic growth factors VEGF$\mathrm{C}$ and VEGF-D. Proteolytic processing of these growth factors by plasmin greatly enhanced their affinity to VEGFR-3 and binding to both VEGFR-2 and VEGFR-3 (McColl et al., 2003).

Numerous other pro-lymphangiogenic factors have been identified in recent years. Among them are ADM, angiopoietin 1 and 2 (Ang-1, Ang-2), COX-2, endothelin-1, fibroblast growth factor2 (FGF-2), growth hormone, heparanase, hepatocyte growth factor (HGF), insulin-like growth factors 1 and 2 (IGF-1, IFG1 ), platelet-derived growth factor-BB (PDGF-BB) and tumor necrosis factor alpha (TNF- $\alpha$ ) (Duong et al., 2012; Ran and Montgomery, 2012). Although these factors have been linked to lymphangiogenesis, the evidence that TAM are expressing them during carcinogenesis as part of their lymphangiogenic activity 
is still insufficient. Future studies will shed light on the role of TAM in the complex control of tumor lymphangiogenesis by the production of cocktails of regulators of lymphangiogenesis.

\section{THE ROLE OF TAM DENSITY IN TUMOR TISSUE AND ITS ASSOCIATION WITH LYMPHANGIOGENESIS}

The idea that TAM regulate tumor lymphangiogenesis is strongly supported by a significant correlation between the density of TAM and LVD in tumor tissues. In human cervical cancer, VEGF-C expressing TAM were found to correlate with increased LVD in peritumoral stroma. All TAM producing VEGF-C were also expressing VEGF-D and VEGFR-3 and were distinguished from other cells by CD68, CD14, CD23, HLA-DR, and CD45 (Schoppmann et al., 2002). In a mouse model of breast cancer, Ito et al. demonstrated a clear correlation between the density of LYVE- $1^{+}$lymphatic vessels, $\mathrm{CD}^{+} 8^{+}$macrophage infiltration, and VEGF-C expression. By comparison of breast cancer cell lines BJMC338 and BJMC3879 having low and high metastatic potential, respectively, more aggressive tumors were found to have an increased infiltration of $\mathrm{CD}^{+} 8^{+}$macrophages, higher expression of VEGF-C and a higher LVD (Ito et al., 2011).

In human breast cancer, higher numbers of TAM expressing VEGF-C were associated with a higher LVD and lymph node metastasis or lymph vessel invasion (LVI) (Ding et al., 2012). Similar results were found in other types of tumors as well. A study on ciliary body melanoma showed a significant correlation between LYVE- ${ }^{+}$and D2-40 ${ }^{+}$intraocular lymphatic vessels, higher $\mathrm{CD}^{+} 8^{+}$macrophage infiltration rate and an increased mortality rate (Heindl et al., 2010). Another study on melanoma revealed a correlation between $\mathrm{CD}^{+} 8^{+}$macrophages and D2$40^{+}$lymphatic vessel invasion, but showed no association with clinical outcomes (Storr et al., 2012). In human skin squamous cell carcinoma, increased LYVE-1 ${ }^{+}$LVD was found to be associated with increased VEGF-C secretion by $\mathrm{CD}^{+}{ }^{+}$and/or $\mathrm{CD} 163^{+}$ macrophages (Moussai et al., 2011). Similar results were obtained by Werchau et al. in a study of Merkel cell carcinoma. Here, VEGF-C secreting $\mathrm{CD}^{+} 8^{+}$and/or $\mathrm{CD} 63^{+}$macrophages were also found to increase LYVE- $1^{+}$or D2-40 ${ }^{+}$LVD (Werchau et al., 2012). Unfortunately, both of these studies failed to provide a prognostic significance for these correlations. In a study of lymphangiogenesis in gastric cancer, $\mathrm{CD} 68^{+}$TAM were shown to be associated with a higher D2-40 ${ }^{+}$LVD and were closely related to serosa invasion and lymph node metastasis (Wu et al., 2012). In pancreatic cancer, VEGF-C expressing M2-polarized macrophages had an association with increased LVD density and incidence of tumor cells in regional lymph nodes (Kurahara et al., 2013).

Positive correlations between the number of TAM, LVD and tumor progression was also demonstrated for lung and esophageal cancers (Ohta et al., 2002; Kurahara et al., 2011; Zhang et al., 2011b). Not all studies were able to show a correlation between TAM, LVD and tumor progression, and some explanation to this phenomenon can be found in a recent review (Ran and Montgomery, 2012). Moreover, our examination of the TAM phenotype in pancreatic insulinoma and melanoma mouse models demonstrated that LYVE-1 can be expressed not only by lymphatic vessels, but also by TAM themselves (Schledzewski et al., 2006). Subtraction of CD68+LYVE+ macrophages has to be done for precise quantification of lymphatic vessels in tumors without counting LYVE-1+ macrophages. LYVE-1 is not the only marker expressed by both TAM and the microvascular cells in tumors. Stabilin-1 is also abundantly expressed on TAM and non-continuous endothelium and probably on lymphatic vessels (Kzhyshkowska et al., 2006b; Martens et al., 2006; Karikoski et al., 2009; Kzhyshkowska, 2010). The available information about the role of TAM in tumor lymphangiogenesis is summarized in Table 1, and a solid body of data indicate that TAM are able to support tumor lymphangiogenesis by direct and indirect effects on EC using a broad spectrum of growth factors, cytokines and enzymes overlapping with pro-angiogenic factors.

\section{CHITINASE-LIKE PROTEINS AS NEW REGULATORS OF TUMOR GROWTH AND VASCULARIZATION}

Recently, a new potent inducer of angiogenesis, YKL40, has been reported for several types of cancer (Shao et al., 2009; Faibish et al., 2011; Francescone et al., 2011, 2013). YKL-40 belongs to the family of Glyco_18 containing proteins that comprises chitinases and chitinase-like proteins (CLPs) (Kzhyshkowska et al., 2006c, 2007). Mammalian CLPs include YKL-39, YKL-40, stabilin-1 interacting chitinase-like protein (SI-CLP) and YM1/YM2 (only in rodents) that contain a Glyco_18 domain only; they lack critical amino acids within the catalytic site (Figure 2) and therefore do not exhibit enzymatic activity (Kzhyshkowska et al., 2006c, 2007). Their biological activity is defined by specific interactions mediated by the enzymatically silent Glyco_18 domain. The Glyco_18 domain is characteristic for the evolutionary conserved chitinases, which belong to the family of 18 glycosyl hydrolases. Enzymatically active chitinases catalyze the hydrolysis of chitin, while their evolutionary conserved function in lower life forms is to provide host defense against chitin-containing organisms (Arakane and Muthukrishnan, 2010). However, at the moment we have only limited information about the biological functions of enzymatically silent CLPs that are induced during inflammation and cancer. Major cell types that express CLPs are macrophages and tumor cells. CLPs are secreted in the extracellular space and therefore can mediate cellular crass-talk. CLPs can also be found in circulation and can act both locally and systemically.

YKL-40, also called human cartilage glycoprotein-39 (HCgp39), gp38k and Chitinase-3-like-1 (CHI3L1), is the best investigated human chitinase-like protein regarding its association with various disorders. Increased concentrations of YKL-40 in circulation are associated with disorders characterized by different types of inflammation and active tissue remodeling, including asthma, arthritis, atherosclerosis and other cardiovascular disorders (Wang et al., 2008; Kastrup, 2011; Harutyunyan et al., 2012; Jensen et al., 2013; Konradsen et al., 2013). Circulating YKL-40 can be detected in human serum or plasma using RIA based on polyclonal antibodies. Most intensively, circulating YKL-40 was investigated in tumor patients (Johansen et al., 2009; Allin et al., 2012). Elevated levels of YKL-40 were found in the circulation of patients with various solid tumors including glioma, breast cancer, colorectal cancer, ovarian cancer, metastatic renal and prostate cancer, and malignant melanoma. In breast cancer 
Table 1 | Role of TAM in tumor lymphangiogenesis and tumor progression.

\begin{tabular}{|c|c|c|c|c|}
\hline Model & TAM phenotype & Action/correlation & Method & References \\
\hline Cervical cancer & $\begin{array}{l}\text { CD68, CD14, CD23, HLA-DR, } \\
\text { and CD45 }\end{array}$ & $\begin{array}{l}\text { Express VEGF-C,VEGF-D, VEGFR-3 } \\
\text { Increased LVD in peritumoral stroma }\end{array}$ & $\begin{array}{l}\text { IHC, IF, Confocal } \\
\text { microscopy }\end{array}$ & $\begin{array}{l}\text { Schoppmann et al., } \\
2002\end{array}$ \\
\hline Lung adenocarcinoma & CD68, CD206 & $\begin{array}{l}\text { Increased LVD, increased lymph node } \\
\text { metastasis rate, poor prognosis }\end{array}$ & $\begin{array}{l}\text { IHC, IF, Confocal } \\
\text { microscopy }\end{array}$ & Zhang et al., 2011b \\
\hline Esophageal carcinoma & CD68 & Increased microvessel density & $\mathrm{IHC}$ & Ohta et al., 2002 \\
\hline Pancreatic cancer & CD68, CD163, CD204 & $\begin{array}{l}\text { Increased LVD in cases with high } \\
\text { number of CD163/CD204 TAM } \\
\text { Increased lymph node metastasis rate } \\
\text { in cases with high number of CD163/ } \\
\text { CD204 TAM }\end{array}$ & $\mathrm{IHC}$ & $\begin{array}{l}\text { Kurahara et al., 2011, } \\
2013\end{array}$ \\
\hline Gastric cancer & CD68 & $\begin{array}{l}\text { Higher LVD } \\
\text { Increased lymph node metastasis rate }\end{array}$ & $\mathrm{IHC}$ & Wu et al., 2012 \\
\hline Merkel cell carcinoma & CD68 and/or CD163 & $\begin{array}{l}\text { VEGF-C expression } \\
\text { Increased LVD }\end{array}$ & $\mathrm{IHC}, \mathrm{IF}$ & Werchau et al., 2012 \\
\hline Skin squamous cell carcinoma & CD68 and/or CD163 & $\begin{array}{l}\text { VEGF-C expression } \\
\text { Increased LVD }\end{array}$ & $\mathrm{IHC}, \mathrm{IF}$ & Moussai et al., 2011 \\
\hline Melanoma & CD68 & Increased LVD & $\mathrm{IHC}$ & Storr et al., 2012 \\
\hline Ciliary body melanoma & CD68 & $\begin{array}{l}\text { Increased LVD } \\
\text { Increased mortality rate }\end{array}$ & $\mathrm{IHC}$ & Heindl et al., 2010 \\
\hline Mouse model of breast cancer & CD68 & Increased LVD and VEGF-C expression & $\mathrm{IHC}$ & Ito et al., 2011 \\
\hline
\end{tabular}

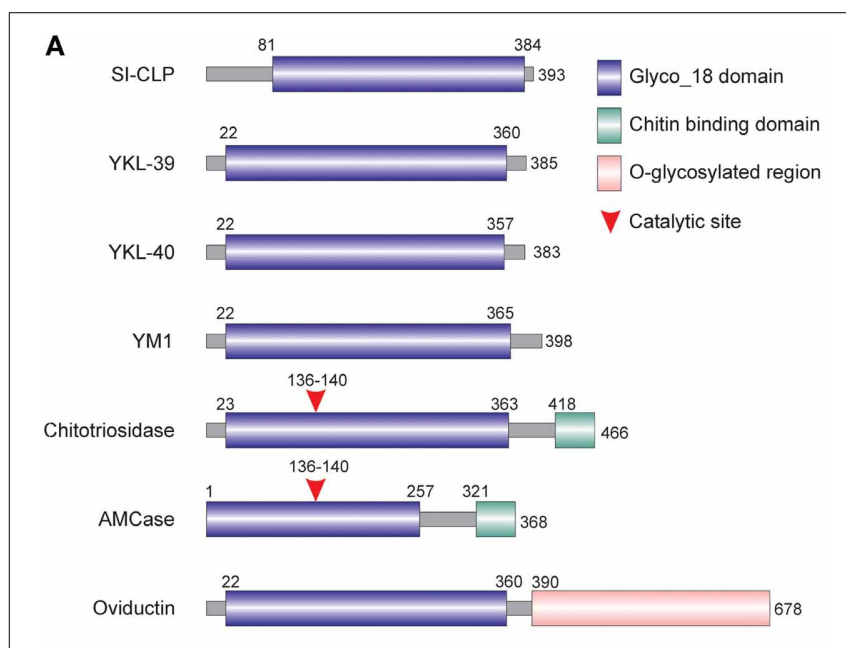

B

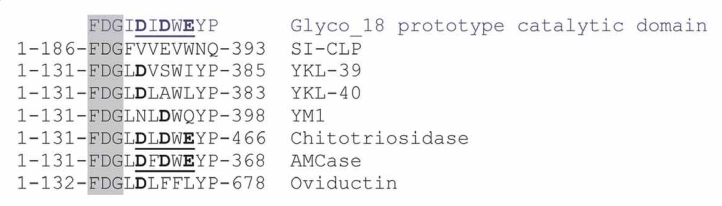

FIGURE 2 | Mammalian chitinase-like proteins (CLP) belong to the family of Glyc_18-containig proteins. (A) Schematic presentation of mammalian Glyco_18 domain containing proteins. (B) Critical amino acid in catalytic sites. The characteristic FDG sequence preceding the catalytic motif is shown in the shadowed box. Catalytic amino acids are shown in bold. Complete active catalytic motifs are underlined. This research was originally published in Blood. Kzhyshkowska et al. (2006c) (c) the American Society of Hematology. patients, high levels of serum YKL-40 are associated with a poor prognosis (Jensen et al., 2003; Johansen et al., 2003; Kim et al., 2007; Yamac et al., 2008; Shao et al., 2011). In primary breast tumors, YKL-40 protein expression was found in tumor cells and in infiltrating inflammatory cells (Roslind et al., 2008). High expression was associated with positive estrogen and progesterone receptor status and high tumor differentiation. Serum levels of YKL-40 are indicative of a poor prognosis and rapid metastatic process. For example, increased plasma concentration of YKL-40 is related to poor prognosis and shorter survival of patients with ovarian cancer, colorectal carcinoma, metastatic prostate carcinoma and melanoma. A recent study demonstrated that YKL-40 expression in anal carcinoma is correlated with a poor outcome and can predict lymph node metastases (Mistrangelo et al., 2013). Differential levels of YKL-40 may reflect differences in the biology of cancer cells themselves, as well as the activation of innate immune responses in primary tumors, in particular, the activity and functional polarization of TAM.

YKL-40 is also the best functionally investigated protein out of all CLPs. Its stimulatory effect on tumor angiogenesis was demonstrated in several studies. Porcine homolog of YKL-40, gp38k (CHI3L1), specifically induces the migration of vascular smooth muscle cells (VSMC), but not fibroblasts. Moreover, gp38k promotes the attachment and spreading of VSMC (Nishikawa and Millis, 2003). Elevated serum levels of YKL-40 are associated with a worse prognosis among various advanced human cancers. Recently YKL-40 was found to act as a strong pro-angiogenic factor in cancer. It has been found that ectopic expression of YKL-40 in MDA-MB-231 breast cancer cells and in HCT116 colon cancer cells led to larger tumor formation with an extensive angiogenic phenotype than did control cancer cells in 
mice. Affinity-purified recombinant YKL-40 protein promoted vascular endothelial cell angiogenesis in vitro, the effects of which are similar to the activities observed using MDA-MB231 and HCT-116 cell-conditioned medium after transfection with YKL-40. Blockade of YKL-40 using small interfering RNA (siRNA) suppressed tumor angiogenesis in vitro and in vivo. Immunohistochemical analysis of human breast cancer showed a correlation between YKL-40 expression and blood vessel density (Shao et al., 2009). Furthermore, a potential receptor for chitinase-like protein was identified for the first time in this study. YKL-40 is a heparin-binding protein and syndecans are a major source of cell surface heparin sulfate (HS). HS functions as a key mediator connecting membrane receptors with extracellular heparin-binding proteins, such as ECM protein vitronectin and angiogenic factors (FGF, VEGF) (Lambaerts et al., 2009). Shao et al. showed that YKL-40 induces a coordination of membrane-bound receptor syndecan- 1 and integrin alpha ${ }_{v}$ beta $_{3}$ and activates an intracellular signaling cascade, including focal adhesion kinase and the MAP/Erk pathway (Shao et al., 2009). YKL-40 also stimulates VEGF expression in U87 glioblastoma cell line cells and synergistically with VEGF promote angiogenesis (Francescone et al., 2011). YKL-40 is also able to enhance contact of tumor and EC, to restrict vascular leakage and stabilize vascular networks (Francescone et al., 2013).

Blocking of YKL-40 activity with monoclonal antibodies demonstrated that this can be a promising therapeutic strategy for advanced tumors (Faibish et al., 2011). A mouse monoclonal antiYKL-40 antibody (mAY) abolished YKL-40-induced activation of VEGF receptor 2 (Flk-1/KDR) and MAP-mediated intracellular signaling, and abrogated angiogenesis induced by YKL-40 conditioned medium of the glioblastoma cell line U87 with elevated levels of YKL-40 induced by $\gamma$-irradiation. Consequently, treatment of xenografted tumor mice with mAY suppressed tumor growth and angiogenesis (Faibish et al., 2011). More information about the mode of action of YKL-40 in tumors and its prognostic and therapeutic value can be found in the recent review of Shao (2013).

YKL-39 was identified as an abundantly secreted protein in primary culture of human articular chondrocytes (Halin et al., 2009). YKL-39 is currently recognized as a biomarker for the activation of chondrocytes and osteoarthritis (OA) progression in humans. YKL-39 might be an inducer of autoimmune processes related to arthritis, while antibodies against YKL-39 were found in patients with rheumatoid arthritis (RA) and OA (reviewed in Kzhyshkowska et al., 2007). For a long time, it was believed that macrophages do not secrete YKL-39. However, recently we demonstrated that the key regulatory factor of tumor progression, TGFß, strongly stimulates YKL-39 expression in macrophages in vitro (Gratchev et al., 2008) suggesting that YKL39 might be a biomarker for subpopulations of macrophages that underwent programming by TGFß in the tumor microenvironment. However expression of YKL39 on macrophages in vivo remains to be examined experimentally.

SI-CLP was identified by us as stabilin-1- interacting chitinase-like protein using yeast two-hybrid screening technology (Kzhyshkowska et al., 2006c). In parallel with its sorting receptor stabilin-1, expression of SI-CLP mRNA was strongly upregulated in macrophages stimulated by Th2 cytokine IL-4 and by dexamethasone. We developed a rat monoclonal antibody, $1 \mathrm{C} 11$, recognizing the N-terminal epitope of SI-CLP. This epitope is located upstream of the conservative Glyco_18 domain and has no similarity with sequences of other human Glyco_18 containing proteins. Using the $1 \mathrm{C} 11$ antibody, we demonstrated that the combination of IL-4 and dexamethasone increases SI-CLP expression in macrophages. $1 \mathrm{C} 11 \mathrm{mAb}$ recognized SI-CLP in the cellular fraction of bronchoalveolar lavage specimens obtained from patients with chronic inflammatory disorders of the respiratory tract and in peripheral blood leukocytes (PBLs) from these patients. SI-CLP is the only chitinase-like protein which is upregulated by glucocorticoids. However, the expression of SI-CLP in tumor cells and TAM, and role of SI-CLP in cancer remain to be investigated.

In summary, the identification of YKL-40 as a pro-angiogenic factor in animal models and in vitro studies opens a new field of investigation of the specific role of CLPs in regulation of tumor growth and angiogenesis. The role of YKL-39 and SI-CLP in tumor angiogenesis has not been reported up to date, however their homology with YKL-40 makes these proteins attractive candidates for the analysis of their effects on tumor angiogenesis and such studies are in progress in our laboratory. The ability of multiple macrophage-derived pro-angiogenic factors to induce growth of both lymphatic and blood vessels raises the possibility for the involvement of YKL-40 and other CLPs proteins in the tumor lymphangiogenesis. Further experimental efforts are required in order to address the role of CLPs in lymphangiogenesis.

\section{CONCLUSIONS AND PERSPECTIVES}

There are no doubts today that TAM are critical controllers of both tumor angiogenesis and lymphangiogenesis. They produce soluble factors which either directly induce vessel formation or enhance production of angiogenic factors by tumor cells. TAMmediated support of vessel growth is associated with increased tumor growth and metastasis. Thus, targeting of TAM appears to be a promising approach for tumor therapy and can be achieved on both cellular and molecular levels. First, complete systemic depletion of macrophages can be performed. However, this approach raises significant concerns since prolonged absence of these cells in organs and circulation may result in sensitization to bacterial infections, and affect functionality of the whole immune system.

Another possibility is to block the recruitment of specific pro-angiogenic TAM populations into tumor site. Analysis of published data suggests that the disruption of CXCL12-CXCR4, ANG2-TIE2, and VEGF-VEGFR axes can prevent infiltration of tumors by angiogenic TAM populations. This approach appears to be promising to inhibit the repopulation of hypoxic tumor areas by TAM after therapeutic interventions. Finally, proangiogenic activity of TAM is based on, but not limited by, the release of common angiogenic factors such as VEGF-A and MMP9. Recent reports reveal novel TAM-derived angiogenic factors including ADM, Sema4D, and YKL-40 in specific tumor types. Thus, it is possible that a tumor-specific microenvironment induces the expression of distinct pro-angiogenic programs in TAM depending on tumor type and affected organ. Therefore, 
the identification of novel TAM-derived angiogenic factors and the validation of their targeting in specific types of cancer is urgently needed. The limitation of this method is related to the fact that TAM release a cocktail of pro-angiogenic factors, and targeting of single factor can be insufficient for suppression of tumor vascularization. Macrophages are not terminally differentiated and show high level of plasticity that makes TAM attractive targets for therapeutic immunomodulation (Stout and Suttles, 2004; Gratchev et al., 2006; Stout et al., 2009). Manipulating TAM phenotype and their re-polarization from pro-angiogenic M2 into anti-angiogenic M1 cells is an advanced strategy to solve this problem. HIF-1, COX-2, and NF-kB can be considered as promising target molecules for macrophages re-polarization. Moreover, correction of macrophage polarization in combination with targeting of single soluble factors, despite being sophisticated and requiring solid experimental investment, opens new horizons for an efficient and personalized cancer therapy.

\section{ACKNOWLEDGMENTS}

This work was supported by the ERA.Net RUS grant DTESTCLP (for Julia Kzhyshkowska and Alexander Orekhov), RFFI 1104-01666-à (for Julia Kzhyshkowska) and the Chinese Research Scholarship (for Nan Wang).

\section{REFERENCES}

Algars, A., Irjala, H., Vaittinen, S., Huhtinen, H., Sundstrom, J., Salmi, M., et al. (2012). Type and location of tumor-infiltrating macrophages and lymphatic vessels predict survival of colorectal cancer patients. Int. J. Cancer 131, 864-873. doi: 10.1002/ijc. 26457

Allavena, P., Sica, A., Solinas, G., Porta, C., and Mantovani, A. (2008). The inflammatory micro-environment in tumor progression: the role of tumor-associated macrophages. Crit. Rev. Oncol. Hematol. 66, 1-9. doi: 10.1016/j.critrevonc.2007.07.004

Allin, K. H., Bojesen, S. E., Johansen, J. S., and Nordestgaard, B. G. (2012). Cancer risk by combined levels of YKL- 40 and C-reactive protein in the general population. Br. J. Cancer 106, 199-205. doi: 10.1038/bjc.2011.501

Arakane, Y., and Muthukrishnan, S. (2010). Insect chitinase and chitinase-like proteins. Cell. Mol. Life Sci. 67, 201-216. doi: 10.1007/s00018-009-0161-9

Basire, A., Sabatier, F., Ravet, S., Lamy, E., Mialhe, A., Zabouo, G., et al. (2006). High urokinase expression contributes to the angiogenic properties of endothelial cells derived from circulating progenitors. Thromb. Haemost. 95, 678-688. doi: 10.1160/TH05-07-0511

Bergers, G., Brekken, R., McMahon, G., Vu, T. H., Itoh, T., Tamaki, K., et al. (2000). Matrix metalloproteinase- 9 triggers the angiogenic switch during carcinogenesis. Nat. Cell Biol. 2, 737-744. doi: 10.1038/35036374

Bijnsdorp, I. V., Capriotti, F., Kruyt, F. A., Losekoot, N., Fukushima, M., Griffioen AW., et al. (2011). Thymidine phosphorylase in cancer cells stimulates human endothelial cell migration and invasion by the secretion of angiogenic factors. Br. J. Cancer 104, 1185-1192. doi: 10.1038/bjc.2011.74

Bingle, L., Brown, N. J., and Lewis, C. E. (2002). The role of tumour-associated macrophages in tumour progression: implications for new anticancer therapies. J. Pathol. 196, 254-265. doi: 10.1002/path.1027

Bjorndahl, M. A., Cao, R., Burton, J. B., Brakenhielm, E., Religa, P., Galter, D., et al. (2005a). Vascular endothelial growth factor-a promotes peritumoral lymphangiogenesis and lymphatic metastasis. Cancer Res. 65, 9261-9268. doi: 10.1158/0008-5472.CAN-04-2345

Bjorndahl, M., Cao, R., Nissen, L. J., Clasper, S., Johnson, L. A., Xue, Y., et al. (2005b). Insulin-like growth factors 1 and 2 induce lymphangiogenesis in vivo. Proc. Natl. Acad. Sci. U.S.A. 102, 15593-15598. doi: 10.1073/pnas.0507865102

Brecht, K., Weigert, A., Hu, J., Popp, R., Fisslthaler, B., Korff, T., et al. (2011). Macrophages programmed by apoptotic cells promote angiogenesis via prostaglandin E2. FASEB J. 25, 2408-2417. doi: 10.1096/fj.10-179473

Burke, B., Tang, N., Corke, K. P., Tazzyman, D., Ameri, K., Wells, M., et al. (2002). Expression of HIF-1alpha by human macrophages: implications for the use of macrophages in hypoxia-regulated cancer gene therapy. J. Pathol. 196, 204-212. doi: 10.1002/path.1029

Cao, Y., Linden, P., Farnebo, J., Cao, R., Eriksson, A., Kumar, V., et al. (1998). Vascular endothelial growth factor $\mathrm{C}$ induces angiogenesis in vivo. Proc. Natl. Acad. Sci. U.S.A. 95, 14389-14394. doi: 10.1073/pnas.95.24.14389

Casazza, A., Laoui, D., Wenes, M., Rizzolio, S., Bassani, N., Mambretti, M., et al. (2013). Impeding macrophage entry into hypoxic tumor areas by sema3a/Nrp1 Signaling blockade inhibits angiogenesis and restores antitumor immunity. Cancer Cell 24, 695-709. doi: 10.1016/j.ccr.2013.11.007

Chen, J. J., Yao, P. L., Yuan, A., Hong, T. M., Shun, C. T., Kuo, M. L., et al. (2003). Up-regulation of tumor interleukin-8 expression by infiltrating macrophages: its correlation with tumor angiogenesis and patient survival in non-small cell lung cancer. Clin. Cancer Res. 9, 729-737.

Chen, P., Huang, Y., Bong, R., Ding, Y., Song, N., Wang, X., et al. (2011). Tumor-associated macrophages promote angiogenesis and melanoma growth via adrenomedullin in a paracrine and autocrine manner. Clin. Cancer Res. 17, 7230-7239. doi: 10.1158/1078-0432.CCR-11-1354

Chen, W., Ma, T., Shen, X. N., Xia, X. F., Xu, G. D., Bai X. L., et al. (2012). Macrophage-induced tumor angiogenesis is regulated by the TSC2-mTOR pathway. Cancer Res. 72, 1363-1372. doi: 10.1158/0008-5472.CAN-11-2684

Coffelt, S. B., Chen, Y. Y., Muthana, M., Welford, A. F., Tal, A. O., Scholz, A., et al. (2011). Angiopoietin 2 stimulates TIE2-expressing monocytes to suppress T cell activation and to promote regulatory T cell expansion. J. Immunol. 186, 4183-4190. doi: 10.4049/jimmunol.1002802

Coffelt, S. B., Hughes, R., and Lewis, C. E. (2009). Tumor-associated macrophages: effectors of angiogenesis and tumor progression. Biochim. Biophys. Acta 1796, 11-18. doi: 10.1016/j.bbcan.2009.02.004

Coffelt, S. B., Tal, A. O., Scholz, A., De Palma, M., Patel, S., Urbich, C., et al. (2010). Angiopoietin-2 regulates gene expression in TIE2-expressing monocytes and augments their inherent proangiogenic functions. Cancer Res. 70, 5270-5280. doi: 10.1158/0008-5472.CAN-10-0012

Cursiefen, C., Chen, L., Borges, L. P., Jackson, D., Cao, J., Radziejewski, C., et al. (2004). VEGF-A stimulates lymphangiogenesis and hemangiogenesis in inflammatory neovascularization via macrophage recruitment. J. Clin. Invest. 113, 1040-1050. doi: 10.1172/JCI20465

David, C., Nance, J. P., Hubbard, J., Hsu, M., Binder, D., and Wilson, E. H. (2012) Stabilin-1 expression in tumor associated macrophages. Brain Res. 1481, 71-78. doi: 10.1016/j.brainres.2012.08.048

De Palma, M., Coukos, G., and Hanahan, D. (2013). A new twist on radiation oncology: low-dose irradiation elicits immunostimulatory macrophages that unlock barriers to tumor immunotherapy. Cancer Cell 24, 559-561. doi: 10.1016/j.ccr.2013.10.019

De Palma, M., Venneri, M. A., Galli, R., Sergi, S. L., Politi, L. S., Sampaolesi, M., et al. (2005). Tie2 identifies a hematopoietic lineage of proangiogenic monocytes required for tumor vessel formation and a mesenchymal population of pericyte progenitors. Cancer Cell 8, 211-226. doi: 10.1016/j.ccr.2005.08.002

Detry, B., Erpicum, C., Paupert, J., Blacher, S., Maillard, C., Bruyere, F., et al. (2012). Matrix metalloproteinase-2 governs lymphatic vessel formation as an interstitial collagenase. Blood 119, 5048-5056. doi: 10.1182/blood-2011-12-400267

Ding, M., Fu, X., Tan, H., Wang, R., Chen, Z., and Ding, S. (2012). The effect of vascular endothelial growth factor $\mathrm{C}$ expression in tumor-associated macrophages on lymphangiogenesis and lymphatic metastasis in breast cancer. Mol. Med. Rep. 6, 1023-1029. doi: 10.3892/mmr.2012.1043

Du, R., Lu, K. V., Petritsch, C., Liu, P., Ganss, R., Passegue, E., et al. (2008). HIFlalpha induces the recruitment of bone marrow-derived vascular modulatory cells to regulate tumor angiogenesis and invasion. Cancer Cell 13, 206-220. doi: 10.1016/j.ccr.2008.01.034

Duong, T., Koopman, P., and Francois, M. (2012). Tumor lymphangiogenesis as a potential therapeutic target. J. Oncol. 2012:204946. doi: 10.1155/2012/204946

Egami, K., Murohara, T., Shimada, T., Sasaki, K., Shintani, S., Sugaya, T., et al. (2003). Role of host angiotensin II type 1 receptor in tumor angiogenesis and growth. J. Clin. Invest. 112, 67-75. doi: 10.1172/JCI16645

Espinosa, I., Edris, B., Lee, C. H., Cheng, H. W., Gilks, C. B., Wang, Y., et al. (2011). CSF1 expression in nongynecological leiomyosarcoma is associated with increased tumor angiogenesis. Am. J. Pathol. 179, 2100-2107. doi: 10.1016/j.ajpath.2011.06.021

Eubank, T. D., Galloway, M., Montague, C. M., Waldman, W. J., and Marsh, C. B. (2003). M-CSF induces vascular endothelial growth factor production and angiogenic activity from human monocytes. J. Immunol. 171, 2637-2643. 
Eubank, T. D., Roda, J. M., Liu, H., O’Neil, T., and Marsh, C. B. (2011). Opposing roles for HIF-1alpha and HIF-2alpha in the regulation of angiogenesis by mononuclear phagocytes. Blood 117, 323-332. doi: 10.1182/blood-2010-01261792

Faibish, M., Francescone, R., Bentley, B., Yan, W., and Shao, R. (2011). A YKL-40neutralizing antibody blocks tumor angiogenesis and progression: a potential therapeutic agent in cancers. Mol. Cancer Ther. 10, 742-751. doi: 10.1158/15357163.MCT-10-0868

Forssell, J., Oberg, A., Henriksson, M. L., Stenling, R., Jung, A., and Palmqvist, R. (2007). High macrophage infiltration along the tumor front correlates with improved survival in colon cancer. Clin. Cancer Res. 13, 1472-1479. doi: 10.1158/1078-0432.CCR-06-2073

Francescone, R. A., Scully, S., Faibish, M., Taylor, S. L., Oh, D., Moral, L., et al. (2011). Role of YKL-40 in the angiogenesis, radioresistance, and progression of glioblastoma. J. Biol. Chem. 286, 15332-15343. doi: 10.1074/jbc.M110.212514

Francescone, R., Ngernyuang, N., Yan, W., Bentley, B., and Shao, R. (2013). Tumorderived mural-like cells coordinate with endothelial cells: role of YKL-40 in mural cell-mediated angiogenesis. Oncogene. doi: 10.1038/onc.2013.160. [Epub ahead of print].

Galarneau, H., Villeneuve, J., Gowing, G., Julien, J. P., and Vallieres, L. (2007). Increased glioma growth in mice depleted of macrophages. Cancer Res. 67, 8874-8881. doi: 10.1158/0008-5472.CAN-07-0177

Giraudo, E., Inoue, M., and Hanahan, D. (2004). An amino-bisphosphonate targets MMP-9-expressing macrophages and angiogenesis to impair cervical carcinogenesis. J. Clin. Invest. 114, 623-633. doi: 10.1172/JCI200 422087

Gomes, F. G., Nedel, F., Alves, A. M., Nor, J. E., and Tarquinio, S. B. (2013). Tumor angiogenesis and lymphangiogenesis: tumor/endothelial crosstalk and cellular/microenvironmental signaling mechanisms. Life Sci. 92, 101-107. doi: 10.1016/j.lfs.2012.10.008

Gordon, E. J., Rao, S., Pollard, J. W., Nutt, S. L., Lang, R. A., and Harvey, N. L. (2010). Macrophages define dermal lymphatic vessel calibre during development by regulating lymphatic endothelial cell proliferation. Development 137, 3899-3910. doi: 10.1242/dev.050021

Gratchev, A., Kzhyshkowska, J., Kothe, K., Muller-Molinet, I., Kannookadan, S., Utikal, J., et al. (2006). Mphil and Mphi2 can be re-polarized by Th2 or Th1 cytokines, respectively, and respond to exogenous danger signals. Immunobiology 211, 473-486. doi: 10.1016/j.imbio.2006.05.017

Gratchev, A., Schmuttermaier, C., Mamidi, S., Gooi, L., Goerdt, S., and Kzhyshkowska, J. (2008). Expression of osteoarthritis marker YKL-39 is stimulated by transforming growth factor beta (TGF-beta) and IL-4 in differentiating macrophages. Biomark. Insights 3, 39-44.

Halin, S., Rudolfsson, S. H., van Rooijen, N., and Bergh, A. (2009). Extratumoral macrophages promote tumor and vascular growth in an orthotopic rat prostate tumor model. Neoplasia 11, 177-186.

Harbeck, N., Schmitt, M., Kates, R. E., Kiechle, M., Zemzoum, I., Janicke, F., et al. (2002). Clinical utility of urokinase-type plasminogen activator and plasminogen activator inhibitor-1 determination in primary breast cancer tissue for individualized therapy concepts. Clin. Breast Cancer 3, 196-200. doi: 10.3816/CBC.2002.n.023

Harutyunyan, M., Christiansen, M., Johansen, J. S., Kober, L., Torp-Petersen, C., and Kastrup, J. (2012). The inflammatory biomarker YKL-40 as a new prognostic marker for all-cause mortality in patients with heart failure. Immunobiology 217, 652-656. doi: 10.1016/j.imbio.2011.11.003

Harutyunyan, M., Gotze, J. P., Winkel, P., Johansen, J. S., Hansen, J. F., Jensen G. B., et al. (2013). Serum YKL-40 predicts long-term mortality in patients with stable coronary disease: a prognostic study within the CLARICOR trial. Immunobiology 218, 945-951. doi: 10.1016/j.imbio.2012.10.015

He, H., Xu, J., Warren, C. M., Duan, D., Li, X., Wu, L., et al. (2012). Endothelial cells provide an instructive niche for the differentiation and functional polarization of M2-like macrophages. Blood 120, 3152-3162. doi: 10.1182/blood-2012-04422758

Heindl, L. M., Hofmann, T. N., Adler, W., Knorr, H. L., Holbach, L. M., Naumann G. O., et al. (2010). Intraocular tumor-associated lymphangiogenesis a novel prognostic factor for ciliary body melanomas with extraocular extension? Ophthalmology 117, 334-342. doi: 10.1016/j.ophtha.2009.06.057

Hildenbrand, R., Dilger, I., Horlin, A., and Stutte, H. J. (1995). Urokinase and macrophages in tumour angiogenesis. Br. J. Cancer 72, 818-823. doi: 10.1038/bjc. 1995.419
Hirakawa, S., Kodama, S., Kunstfeld, R., Kajiya, K., Brown, L. F., and Detmar, M. (2005). VEGF-A induces tumor and sentinel lymph node lymphangiogenesis and promotes lymphatic metastasis. J. Exp. Med. 201, 1089-1099. doi: 10.1084/jem.20041896

Hong, T. M., Teng, L. J., Shun, C. T., Peng, M. C., and Tsai, J. C. (2009). Induced interleukin- 8 expression in gliomas by tumor-associated macrophages. J. Neurooncol. 93, 289-301. doi: 10.1007/s11060-008-9786-Z

Hong, Y. K., Lange-Asschenfeldt, B., Velasco, P., Hirakawa, S., Kunstfeld, R., Brown L. F., et al. (2004). VEGF-A promotes tissue repair-associated lymphatic vessel formation via VEGFR-2 and the alphalbetal and alpha2betal integrins. FASEB J. 18, 1111-1113.

Hotchkiss, K. A., Ashton, A. W., and Schwartz, E. L. (2003). Thymidine phosphorylase and 2-deoxyribose stimulate human endothelial cell migration by specific activation of the integrins alpha 5 beta 1 and alpha V beta 3. J. Biol. Chem. 278, 19272-19279. doi: 10.1074/jbc.M212670200

Huang, H., Lai, J. Y., Do, J., Liu, D., Li, L., Del Rosario, J., et al. (2011). Specifically targeting angiopoietin-2 inhibits angiogenesis, Tie2-expressing monocyte infiltration, and tumor growth. Clin. Cancer Res. 17, 1001-1011. doi: 10.1158/10780432.CCR-10-2317

Huang, S., Van Arsdall, M., Tedjarati, S., McCarty, M., Wu, W., Langley, R., et al. (2002). Contributions of stromal metalloproteinase- 9 to angiogenesis and growth of human ovarian carcinoma in mice. J. Natl. Cancer Inst. 94, 1134-1142. doi: 10.1093/jnci/94.15.1134

Imtiyaz, H. Z., Williams, E. P., Hickey, M. M., Patel, S. A., Durham, A. C., Yuan LJ., et al. (2010). Hypoxia-inducible factor 2 alpha regulates macrophage function in mouse models of acute and tumor inflammation. J. Clin. Invest. 120, 2699-2714. doi: 10.1172/JCI39506

Ito, Y., Shibata, M. A., Eid, N., Morimoto, J., and Otsuki, Y. (2011). Lymphangiogenesis and axillary lymph node metastases correlated with VEGF$\mathrm{C}$ expression in two immunocompetent mouse mammary carcinoma models. Int. J. Breast Cancer 2011:867152. doi: 10.4061/2011/867152

Jensen, B. V., Johansen, J. S., and Price, P. A. (2003). High levels of serum HER2/neu and YKL-40 independently reflect aggressiveness of metastatic breast cancer. Clin. Cancer Res. 9, 4423-4434.

Jensen, P., Wiell, C., Milting, K., Poggenborg, R. P., Ostergaard, M., Johansen JS., et al. (2013). Plasma YKL-40: a potential biomarker for psoriatic arthritis? J. Eur. Acad. Dermatol. Venereol. 27, 815-819. doi: 10.1111/j.1468-3083. 2012.04570.x

Jeon, B. H., Jang, C., Han, J., Kataru, R. P., Piao, L., Jung, K., et al. (2008). Profound but dysfunctional lymphangiogenesis via vascular endothelial growth factor ligands from CD11b+ macrophages in advanced ovarian cancer. Cancer Res. 68, 1100-1109. doi: 10.1158/0008-5472.CAN-07-2572

Jeon, S. H., Chae, B. C., Kim, H. A., Seo, G. Y., Seo, D. W., Chun GT., et al. (2007). Mechanisms underlying TGF-betal-induced expression of VEGF and Flk-1 in mouse macrophages and their implications for angiogenesis. J. Leukoc. Biol. 81, 557-566. doi: 10.1189/jlb.0806517

Johansen, J. S., Christensen, I. J., Riisbro, R., Greenall, M., Han, C., Price, P. A., et al. (2003). High serum YKL-40 levels in patients with primary breast cancer is related to short recurrence free survival. Breast Cancer Res. Treat. 80, 15-21. doi: 10.1023/A:1024431000710

Johansen, J. S., Schultz, N. A., and Jensen, B. V. (2009). Plasma YKL-40: a potential new cancer biomarker? Future Oncol. 5, 1065-1082. doi: 10.2217/fon.09.66

Joukov, V., Sorsa, T., Kumar, V., Jeltsch, M., Claesson-Welsh, L., Cao, Y., et al. (1997). Proteolytic processing regulates receptor specificity and activity of VEGF-C. EMBO J. 16, 3898-3911. doi: 10.1093/emboj/16.13.3898

Jung, Y. J., Isaacs, J. S., Lee, S., Trepel, J., and Neckers, L. (2003). IL-1beta-mediated up-regulation of HIF-1alpha via an NFkappaB/COX-2 pathway identifies HIF1 as a critical link between inflammation and oncogenesis. FASEB J. 17, 2115-2117.

Karikoski, M., Irjala, H., Maksimow, M., Miiluniemi, M., Granfors, K. Hernesniemi, S., et al. (2009). Clever-1/Stabilin-1 regulates lymphocyte migration within lymphatics and leukocyte entrance to sites of inflammation. Eur. J. Immunol. 39, 3477-3487. doi: 10.1002/eji.200939896

Kastrup, J. (2011). Can YKL-40 be a new inflammatory biomarker in cardiovascular disease? Immunobiology 217, 483-491. doi: 10.1016/j.imbio.2011.04.007

Kawahara, A., Hattori, S., Akiba, J., Nakashima, K., Taira, T., Watari, K., et al. (2010). Infiltration of thymidine phosphorylase-positive macrophages is closely associated with tumor angiogenesis and survival in intestinal type gastric cancer. Oncol. Rep. 24, 405-415. doi: 10.3892/or_00000873 
Kerjaschki, D. (2005). The crucial role of macrophages in lymphangiogenesis. J. Clin. Invest. 115, 2316-2319. doi: 10.1172/JCI26354

Kim, S. H., Das, K., Noreen, S., Coffman, F., and Hameed, M. (2007). Prognostic implications of immunohistochemically detected YKL-40 expression in breast cancer. World J. Surg. Oncol. 5:17. doi: 10.1186/1477-7819-5-17

Kioi, M., Vogel, H., Schultz, G., Hoffman, R. M., Harsh, G. R., and Brown, J. M. (2010). Inhibition of vasculogenesis, but not angiogenesis, prevents the recurrence of glioblastoma after irradiation in mice. J. Clin. Invest. 120, 694-705. doi: $10.1172 /$ JCI 40283

Klug, F., Prakash, H., Huber, P. E., Seibel, T., Bender, N., Halama, N., et al. (2013). Low-dose irradiation programs macrophage differentiation to an iNOS(+)/M1 phenotype that orchestrates effective T Cell immunotherapy. Cancer Cell 24, 589-602. doi: 10.1016/j.ccr.2013.09.014

Konradsen, J. R., James, A., Nordlund, B., Reinius, L. E., Soderhall, C., Melen, E., et al. (2013). The chitinase-like protein YKL-40: A possible biomarker of inflammation and airway remodeling in severe pediatric asthma. J. Allergy. Clin. Immunol. 132, 328-335. doi: 10.1016/j.jaci.2013.03.003

Kozin, S. V., Kamoun, W. S., Huang, Y., Dawson, M. R., Jain, R. K., and Duda, D. G. (2010). Recruitment of myeloid but not endothelial precursor cells facilitates tumor regrowth after local irradiation. Cancer Res. 70, 5679-5685. doi: 10.1158/0008-5472.CAN-09-4446

Kurahara, H., Shinchi, H., Mataki, Y., Maemura, K., Noma, H., Kubo, F., et al. (2011). Significance of M2-polarized tumor-associated macrophage in pancreatic cancer. J. Surg. Res. 167, e211-e219. doi: 10.1016/j.jss.2009.05.026

Kurahara, H., Takao, S., Maemura, K., Mataki, Y., Kuwahata, T., Maeda, K., et al. (2013). M2-polarized tumor-associated macrophage infiltration of regional lymph nodes is associated with nodal lymphangiogenesis and occult nodal involvement in pN0 pancreatic cancer. Pancreas 42, 155-159. doi: 10.1097/MPA.0b013e318254f2d1

Kwon, S. J., Lee, G. T., Lee, J. H., Iwakura, Y., Kim, W. J., and Kim, I. Y. (2013). Mechanism of pro-tumorigenic effect of BMP-6: neovascularization involving tumor-associated macrophages and IL-1alpha. Prostate 74, 121-133. doi: $10.1002 /$ pros. 22734

Kzhyshkowska, J. (2010). Multifunctional receptor stabilin-1 in homeostasis and disease. ScientificWorldJournal 10, 2039-2053. doi: 10.1100/tsw.2010.189

Kzhyshkowska, J., Gratchev, A., and Goerdt, S. (2006b). Stabilin-1, a homeostatic scavenger receptor with multiple functions. J. Cell. Mol. Med. 10, 635-649. doi: 10.1111/j.1582-4934.2006.tb00425.x

Kzhyshkowska, J., and Krusell, L. (2009). Cross-talk between endocytic clearance and secretion in macrophages. Immunobiology 214, 576-593. doi: 10.1016/j.imbio.2009.03.007

Kzhyshkowska, J., Gratchev, A., and Goerdt, S. (2007). Human chitinases and chitinase-like proteins as indicators for inflammation and cancer. Biomark. Insights 2, 128-146.

Kzhyshkowska, J., Mamidi, S., Gratchev, A., Kremmer, E., Schmuttermaier, C., Krusell, L., et al. (2006c). Novel stabilin-1 interacting chitinase-like protein (SI-CLP) is up-regulated in alternatively activated macrophages and secreted via lysosomal pathway. Blood 107, 3221-3228. doi: 10.1182/blood-200507-2843

Kzhyshkowska, J., Workman, G., Cardo-Vila, M., Arap, W., Pasqualini, R., Gratchev, A., et al. (2006a). Novel function of alternatively activated macrophages: stabilin-1-mediated clearance of, SPARC. J. Immunol. 176, 5825-5832.

Lambaerts, K., Wilcox-Adelman, S. A., and Zimmermann, P. (2009). The signaling mechanisms of syndecan heparan sulfate proteoglycans. Curr. Opin. Cell Biol. 21, 662-669. doi: 10.1016/j.ceb.2009.05.002

Laoui, D., Van Overmeire, E., Di Conza, G., Aldeni, C., Keirsse, J., Morias, Y., et al. (2013). Tumor hypoxia does not drive differentiation of tumor-associated macrophages but rather fine-tunes the M2-like macrophage population. Cancer Res. 74, 24-30. doi: 10.1158/0008-5472.CAN-13-1196

Lee, S., Jilani, S. M., Nikolova, G. V., Carpizo, D., and Iruela-Arispe, M. L. (2005). Processing of VEGF-A by matrix metalloproteinases regulates bioavailability and vascular patterning in tumors. J. Cell Biol. 169, 681-691. doi: 10.1083/jcb.200409115

Leek, R. D., Landers, R., Fox, S. B., Ng, F., Harris, A. L., and Lewis, C. E. (1998). Association of tumour necrosis factor alpha and its receptors with thymidine phosphorylase expression in invasive breast carcinoma. Br. J. Cancer 77, 2246-2251. doi: 10.1038/bjc. 1998.373
Leek, R. D., Lewis, C. E., Whitehouse, R., Greenall, M., Clarke, J., and Harris, A. L. (1996). Association of macrophage infiltration with angiogenesis and prognosis in invasive breast carcinoma. Cancer Res. 56, 4625-4629.

Lewis, C. E., De Palma, M., and Naldini, L. (2007). Tie2-expressing monocytes and tumor angiogenesis: regulation by hypoxia and angiopoietin-2. Cancer Res. 67, 8429-8432. doi: 10.1158/0008-5472.CAN-07-1684

Lewis, J. S., Landers, R. J., Underwood, J. C., Harris, A. L., and Lewis, C. E. (2000). Expression of vascular endothelial growth factor by macrophages is up- regulated in poorly vascularized areas of breast carcinomas. J. Pathol. 192, 150-158. doi: 10.1002/1096-9896(2000)9999:9999\%3C::AID-PATH687\%3E3.0.CO;2-G

Lin, E. Y., Li, J. F., Gnatovskiy, L., Deng, Y., Zhu, L., Grzesik D. A., et al. (2006). Macrophages regulate the angiogenic switch in a mouse model of breast cancer. Cancer Res. 66, 11238-11246. doi: 10.1158/0008-5472.CAN-06-1278

Lohela, M., Bry, M., Tammela, T., and Alitalo, K. (2009). VEGFs and receptors involved in angiogenesis versus lymphangiogenesis. Curr. Opin. Cell Biol. 21, 154-165. doi: 10.1016/j.ceb.2008.12.012

Ly, L. V., Baghat, A., Versluis, M., Jordanova, E. S., Luyten, G. P., van Rooijen, N., et al. (2010). In aged mice, outgrowth of intraocular melanoma depends on proangiogenic M2-type macrophages. J. Immunol. 185, 3481-3488. doi: 10.4049/jimmunol.0903479

Mantovani, A., Bottazzi, B., Colotta, F., Sozzani, S., and Ruco, L. (1992). The origin and function of tumor-associated macrophages. Immunol. Today 13, 265-270. doi: 10.1016/0167-5699(92)90008-U

Mantovani, A., Marchesi, F., Porta, C., Sica, A., and Allavena, P. (2007). Inflammation and cancer: breast cancer as a prototype. Breast 16(Suppl. 2), S27-S33. doi: 10.1016/j.breast.2007.07.013

Martens, J. H., Kzhyshkowska, J., Falkowski-Hansen, M., Schledzewski, K., Gratchev, A., Mansmann, U., et al. (2006). Differential expression of a gene signature for scavenger/lectin receptors by endothelial cells and macrophages in human lymph node sinuses, the primary sites of regional metastasis. J. Pathol. 208, 574-589. doi: 10.1002/path.1921

Matsubara, T., Kanto, T., Kuroda, S., Yoshio, S., Higashitani, K., Kakita, N., et al. (2013). TIE2-expressing monocytes as a diagnostic marker for hepatocellular carcinoma correlates with angiogenesis. Hepatology 57, 1416-1425. doi: 10.1002/hep. 25965

Mazzieri, R., Pucci, F., Moi, D., Zonari, E., Ranghetti, A., Berti, A., et al. (2011). Targeting the ANG2/TIE2 axis inhibits tumor growth and metastasis by impairing angiogenesis and disabling rebounds of proangiogenic myeloid cells. Cancer Cell 19, 512-526. doi: 10.1016/j.ccr.2011.02.005

McColl, B. K., Baldwin, M. E., Roufail, S., Freeman, C., Moritz, R. L., Simpson R. J., et al. (2003). Plasmin activates the lymphangiogenic growth factors VEGF-C and VEGF-D. J. Exp. Med. 198, 863-868. doi: 10.1084/jem.20030361

Medina, R. J., O'Neill, C. L., O'Doherty, T. M., Knott, H., Guduric-Fuchs, J., Gardiner TA., et al. (2011). Myeloid angiogenic cells act as alternative M2 macrophages and modulate angiogenesis through interleukin-8. Mol. Med. 17, 1045-1055. doi: 10.2119/molmed.2011.00129

Mistrangelo, M., Senetta, R., Racca, P., Castellano, I., Chiusa, L., Bello, M., et al. (2013). A novel biomarker-based analysis reliably predicts nodal metastases in anal carcinoma: preliminary evidence of therapeutic impact. Colorectal Dis. 15 , 1382-1391. doi: 10.1111/codi.12289

Moussai, D., Mitsui, H., Pettersen, J. S., Pierson, K. C., Shah, K. R., Suarez-Farinas, M., et al. (2011). The human cutaneous squamous cell carcinoma microenvironment is characterized by increased lymphatic density and enhanced expression of macrophage-derived VEGF-C. J. Invest. Dermatol. 131, 229-236. doi: 10.1038/jid.2010.266

Nakamura, E. S., Koizumi, K., Kobayashi, M., and Saiki, I. (2004). Inhibition of lymphangiogenesis-related properties of murine lymphatic endothelial cells and lymph node metastasis of lung cancer by the matrix metalloproteinase inhibitor MMI270. Cancer Sci. 95, 25-31. doi: 10.1111/j.1349-7006.2004.tb 03166.x

Nishie, A., Ono, M., Shono, T., Fukushi, J., Otsubo, M., Onoue, H., et al. (1999). Macrophage infiltration and heme oxygenase- 1 expression correlate with angiogenesis in human gliomas. Clin. Cancer Res. 5, 1107-1113.

Nishikawa, K. C., and Millis, A. J. (2003). gp38k (CHI3L1) is a novel adhesion and migration factor for vascular cells. Exp. Cell Res. 287, 79-87. doi: 10.1016/S00144827(03)00069-7

Ohta, M., Kitadai, Y., Tanaka, S., Yoshihara, M., Yasui, W., Mukaida, N., et al. (2002). Monocyte chemoattractant protein-1 expression correlates with 
macrophage infiltration and tumor vascularity in human esophageal squamous cell carcinomas. Int. J. Cancer 102, 220-224. doi: 10.1002/ijc.10705

Ong, S. M., Tan, Y. C., Beretta, O., Jiang, D., Yeap, W. H., Tai J. J., et al. (2012). Macrophages in human colorectal cancer are pro-inflammatory and prime $\mathrm{T}$ cells towards an anti-tumour type-1 inflammatory response. Eur. J. Immunol. 42, 89-100. doi: 10.1002/eji.201141825

Piao, Y. J., Lee, C. H., Zhu, M. J., Kye, K. C., Kim, J. M., Seo YJ., et al. (2005). Involvement of urokinase-type plasminogen activator in sphingosylphosphorylcholine-induced angiogenesis. Exp. Dermatol. 14, 356-362. doi: 10.1111/j.0906-6705.2005.00272.x

Pucci, F., Venneri, M. A., Biziato, D., Nonis, A., Moi, D., Sica, A., et al. (2009). A distinguishing gene signature shared by tumor-infiltrating Tie2-expressing monocytes, blood "resident" monocytes, and embryonic macrophages suggests common functions and developmental relationships. Blood 114, 901-914. doi: 10.1182/blood-2009-01-200931

Qian, B. Z., and Pollard, J. W. (2010). Macrophage diversity enhances tumor progression and metastasis. Cell 141, 39-51. doi: 10.1016/j.cell.2010.03.014

Ran, S., and Montgomery, K. E. (2012). Macrophage-Mediated Lymphangiogenesis: the emerging role of macrophages as lymphatic endothelial progenitors. Cancers (Basel). 4, 618-657. doi: 10.3390/cancers4030618

Rego, S. L., Helms, R. S., and Dreau, D. (2013). Breast tumor cell TACE-shed MCSF promotes pro-angiogenic macrophages through NF-kappaB signaling. Angiogenesis. doi: 10.1007/s10456-013-9405-2. [Epub ahead of print].

Roberts, N., Kloos, B., Cassella, M., Podgrabinska, S., Persaud, K., Wu, Y., et al. (2006). Inhibition of VEGFR-3 activation with the antagonistic antibody more potently suppresses lymph node and distant metastases than inactivation of VEGFR-2. Cancer Res. 66, 2650-2657. doi: 10.1158/0008-5472.CAN-05-1843

Roda, J. M., Wang, Y., Sumner, L. A., Phillips, G. S., Marsh, C. B., and Eubank, T. D. (2012). Stabilization of HIF-2alpha induces sVEGFR-1 production from tumor-associated macrophages and decreases tumor growth in a murine melanoma model. J. Immunol. 189, 3168-3177. doi: 10.4049/jimmunol. 1103817

Rolny, C., Mazzone, M., Tugues, S., Laoui, D., Johansson, I., Coulon, C., et al. (2011). HRG inhibits tumor growth and metastasis by inducing macrophage polarization and vessel normalization through downregulation of PlGF. Cancer Cell 19, 31-44. doi: 10.1016/j.ccr.2010.11.009

Roslind, A., Knoop, A. S., Jensen, M. B., Johansen, J. S., Nielsen, D. L., Price, P. A., et al. (2008). YKL-40 protein expression is not a prognostic marker in patients with primary breast cancer. Breast Cancer Res. Treat. 112, 275-285. doi: 10.1007/s10549-007-9870-7

Scavelli, C., Vacca, A., Di Pietro, G., Dammacco, F., and Ribatti, D. (2004). Crosstalk between angiogenesis and lymphangiogenesis in tumor progression. Leukemia 18, 1054-1058. doi: 10.1038/sj.leu.2403355

Schledzewski, K., Falkowski, M., Moldenhauer, G., Metharom, P., Kzhyshkowska, J., Ganss, R., et al. (2006). Lymphatic endothelium-specific hyaluronan receptor LYVE-1 is expressed by stabilin-1(+), F4/80(+), CD11b(+) macrophages in malignant tumours and wound healing tissue in vivo and in bone marrow cultures in vitro: implications for the assessment of lymphangiogenesis. J. Pathol. 209, 67-77. doi: 10.1002/path.1942

Schoppmann, S. F., Birner, P., Stockl, J., Kalt, R., Ullrich, R., Caucig, C., et al. (2002). Tumor-associated macrophages express lymphatic endothelial growth factors and are related to peritumoral lymphangiogenesis. Am. J. Pathol. 161, 947-956. doi: 10.1016/S0002-9440(10)64255-1

Schoppmann, S. F., Fenzl, A., Nagy, K., Unger, S., Bayer, G., Geleff, S., et al. (2006). VEGF-C expressing tumor-associated macrophages in lymph node positive breast cancer: impact on lymphangiogenesis and survival. Surgery 139, 839-846. doi: 10.1016/j.surg.2005.12.008

Shao, R. (2013). YKL-40 acts as an angiogenic factor to promote tumor angiogenesis. Front. Physiol. 4:122. doi: 10.3389/fphys.2013.00122

Shao, R., Cao, Q. J., Arenas, R. B., Bigelow, C., Bentley, B., and Yan, W. (2011). Breast cancer expression of YKL-40 correlates with tumour grade, poor differentiation, and other cancer markers. Br. J. Cancer 105, 1203-1209. doi: 10.1038/bjc. 2011.347

Shao, R., Hamel, K., Petersen, L., Cao, Q. J., Arenas, R. B., Bigelow, C., et al. (2009). YKL-40, a secreted glycoprotein, promotes tumor angiogenesis. Oncogene 28, 4456-4468. doi: 10.1038/onc.2009.292

Shieh, Y. S., Hung, Y. J., Hsieh, C. B., Chen, J. S., Chou, K. C., and Liu, S. Y. (2009). Tumor-associated macrophage correlated with angiogenesis and progression of mucoepidermoid carcinoma of salivary glands. Ann. Surg. Oncol. 16, 751-760. doi: 10.1245/s10434-008-0259-6

Sica, A., and Mantovani, A. (2012). Macrophage plasticity and polarization: in vivo veritas. J. Clin. Invest. 122, 787-795. doi: 10.1172/JCI59643

Sierra, J. R., Corso, S., Caione, L., Cepero, V., Conrotto, P., Cignetti, A., et al. (2008). Tumor angiogenesis and progression are enhanced by Sema4D produced by tumor-associated macrophages. J. Exp. Med. 205, 1673-1685. doi: 10.1084/jem.20072602

Skobe, M., Hamberg, L. M., Hawighorst, T., Schirner, M., Wolf, G. L., Alitalo, K., et al. (2001b). Concurrent induction of lymphangiogenesis, angiogenesis, and macrophage recruitment by vascular endothelial growth factor- $\mathrm{C}$ in melanoma. Am. J. Pathol. 159, 893-903. doi: 10.1016/S0002-9440(10)61765-8

Skobe, M., Hawighorst, T., Jackson, D. G., Prevo, R., Janes, L., Velasco, P., et al. (2001a). Induction of tumor lymphangiogenesis by VEGF-C promotes breast cancer metastasis. Nat. Med. 7, 192-198. doi: 10.1038/84643

Song, K., Herzog, B. H., Sheng, M., Fu, J., McDaniel, J. M., Ruan, J., et al. (2013). Lenalidomide inhibits lymphangiogenesis in preclinical models of mantle cell lymphoma. Cancer Res. 73, 7254-7264. doi: 10.1158/0008-5472.CAN-13-0750

Stacker, S. A., Stenvers, K., Caesar, C., Vitali, A., Domagala, T., Nice, E., et al. (1999). Biosynthesis of vascular endothelial growth factor-D involves proteolytic processing which generates non-covalent homodimers. J. Biol. Chem. 274, 32127-32136. doi: 10.1074/jbc.274.45.32127

Staples, K. J., Sotoodehnejadnematalahi, F., Pearson, H., Frankenberger, M., Francescut, L., Ziegler-Heitbrock, L., et al. (2011). Monocytederived macrophages matured under prolonged hypoxia transcriptionally up-regulate HIF-1alpha mRNA. Immunobiology 216, 832-839. doi: 10.1016/j.imbio.2010.12.005

Storr, S. J., Safuan, S., Mitra, A., Elliott, F., Walker, C., Vasko MJ., et al. (2012). Objective assessment of blood and lymphatic vessel invasion and association with macrophage infiltration in cutaneous melanoma. Mod. Pathol. 25, 493-504. doi: 10.1038/modpathol.2011.182

Stout, R. D., and Suttles, J. (2004). Functional plasticity of macrophages: reversible adaptation to changing microenvironments. J. Leukoc. Biol. 76, 509-513. doi: 10.1189/jlb.0504272

Stout, R. D., Watkins, S. K., and Suttles, J. (2009). Functional plasticity of macrophages: in situ reprogramming of tumor-associated macrophages. J. Leukoc. Biol. 86, 1105-1109. doi: 10.1189/jlb.0209073

Takanami, I., Takeuchi, K., and Kodaira, S. (1999). Tumor-associated macrophage infiltration in pulmonary adenocarcinoma: association with angiogenesis and poor prognosis. Oncology 57, 138-142. doi: 10.1159/000012021

Takao, S., Takebayashi, Y., Che, X., Shinchi, H., Natsugoe, S., Miyadera, K., et al. (1998). Expression of thymidine phosphorylase is associated with a poor prognosis in patients with ductal adenocarcinoma of the pancreas. Clin. Cancer Res. 4, 1619-1624.

Tammela, T., Zarkada, G., Wallgard, E., Murtomaki, A., Suchting, S., Wirzenius, M., et al. (2008). Blocking VEGFR-3 suppresses angiogenic sprouting and vascular network formation. Nature 454, 656-660. doi: 10.1038/nature 07083

Tjiu, J. W., Chen, J. S., Shun, C. T., Lin, S. J., Liao, Y. H., Chu C. Y., et al. (2009). Tumor-associated macrophage-induced invasion and angiogenesis of human basal cell carcinoma cells by cyclooxygenase- 2 induction. J. Invest. Dermatol. 129, 1016-1025. doi: 10.1038/jid.2008.310

Toi, M., Ueno, T., Matsumoto, H., Saji, H., Funata, N., Koike, M., et al. (1999). Significance of thymidine phosphorylase as a marker of protumor monocytes in breast cancer. Clin. Cancer Res. 5, 1131-1137.

Torisu, H., Ono, M., Kiryu, H., Furue, M., Ohmoto, Y., Nakayama, J., et al. (2000). Macrophage infiltration correlates with tumor stage and angiogenesis in human malignant melanoma: possible involvement of TNFalpha and IL-1alpha. Int. J. Cancer 85, 182-188. doi: 10.1002/(SICI)10970215(20000115)85:2\%3C182::AID-IJC6\%3E3.3.CO;2-D

Vacca, A., Ribatti, D., Ruco, L., Giacchetta, F., Nico, B., Quondamatteo, F., et al. (1999). Angiogenesis extent and macrophage density increase simultaneously with pathological progression in B-cell non-Hodgkin's lymphomas. Br. J. Cancer 79, 965-970. doi: 10.1038/sj.bjc.6690154

Valkovic, T., Dobrila, F., Melato, M., Sasso, F., Rizzardi, C., and Jonjic, N. (2002). Correlation between vascular endothelial growth factor, angiogenesis, and tumor-associated macrophages in invasive ductal breast carcinoma. Virchows Arch. 440, 583-588. doi: 10.1007/s004280100458 
Wang, Y., Ripa, R. S., Johansen, J. S., Gabrielsen, A., Steinbruchel, D. A., Friis, T., et al. (2008). YKL-40 a new biomarker in patients with acute coronary syndrome or stable coronary artery disease. Scand. Cardiovasc. J. 42, 295-302. doi: $10.1080 / 14017430802220567$

Welford, A. F., Biziato, D., Coffelt, S. B., Nucera, S., Fisher, M., Pucci, F., et al. (2011). TIE2-expressing macrophages limit the therapeutic efficacy of the vasculardisrupting agent combretastatin A4 phosphate in mice. J. Clin. Invest. 121, 1969-1973. doi: 10.1172/JCI44562

Werchau, S., Toberer, F., Enk, A., Dammann, R., and Helmbold, P. (2012). Merkel cell carcinoma induces lymphatic microvessel formation. J. Am. Acad. Dermatol. 67, 215-225. doi: 10.1016/j.jaad.2011.09.002

Werno, C., Menrad, H., Weigert, A., Dehne, N., Goerdt, S., Schledzewski, K., et al. (2010). Knockout of HIF-1alpha in tumor-associated macrophages enhances M2 polarization and attenuates their pro-angiogenic responses. Carcinogenesis 31, 1863-1872. doi: 10.1093/carcin/bgq088

Whitehurst, B., Flister, M. J., Bagaitkar, J., Volk, L., Bivens, C. M., Pickett, B., et al. (2007). Anti-VEGF-A therapy reduces lymphatic vessel density and expression of VEGFR-3 in an orthotopic breast tumor model. Int. J. Cancer 121, 2181-2191. doi: 10.1002/ijc.22937

Wu, H., Xu, J. B., He, Y. L., Peng, J. J., Zhang, X. H., Chen C. Q., et al. (2012). Tumor-associated macrophages promote angiogenesis and lymphangiogenesis of gastric cancer. J. Surg. Oncol. 106, 462-468. doi: 10.1002/jso.23110

Wyckoff, J., Wang, W., Lin, E. Y., Wang, Y., Pixley, F., Stanley E. R., et al. (2004). A paracrine loop between tumor cells and macrophages is required for tumor cell migration in mammary tumors. Cancer Res. 64, 7022-7029. doi: 10.1158/00085472.CAN-04-1449

Xu, J., Escamilla, J., Mok, S., David, J., Priceman, S., West, B., et al. (2013). CSF1R signaling blockade stanches tumor-infiltrating myeloid cells and improves the efficacy of radiotherapy in prostate cancer. Cancer Res. 73, 2782-2794. doi: 10.1158/0008-5472.CAN-12-3981

Yamac, D., Ozturk, B., Coskun, U., Tekin, E., Sancak, B., Yildiz, R., et al. (2008). Serum YKL-40 levels as a prognostic factor in patients with locally advanced breast cancer. Adv. Ther. 25, 801-809. doi: 10.1007/s12325-008-0082-2

Yang, H., Kim, C., Kim, M. J., Schwendener, R. A., Alitalo, K., Heston, W., et al. (2011). Soluble vascular endothelial growth factor receptor-3 suppresses lymphangiogenesis and lymphatic metastasis in bladder cancer. Mol. Cancer 10:36. doi: 10.1186/1476-4598-10-36

Yao, P. L., Lin, Y. C., Wang, C. H., Huang, Y. C., Liao, W. Y., Wang, S. S., et al. (2005). Autocrine and paracrine regulation of interleukin-8 expression in lung cancer cells. Am. J. Respir. Cell Mol. Biol. 32, 540-547. doi: 10.1165/rcmb.2004$0223 \mathrm{OC}$
Yao, Y., Kubota, T., Sato, K., and Kitai, R. (2001). Macrophage infiltrationassociated thymidine phosphorylase expression correlates with increased microvessel density and poor prognosis in astrocytic tumors. Clin. Cancer Res. 7, 4021-4026.

Zhang, B., Yao, G., Zhang, Y., Gao, J., Yang, B., Rao, Z., et al. (2011b). M2polarized tumor-associated macrophages are associated with poor prognoses resulting from accelerated lymphangiogenesis in lung adenocarcinoma. Clinics (Sao. Paulo). 66, 1879-1886. doi: 10.1590/S1807-59322011001100006

Zhang, B., Zhang, Y., Yao, G., Gao, J., Yang, B., Zhao, Y., et al. (2012b). M2-polarized macrophages promote metastatic behavior of Lewis lung carcinoma cells by inducing vascular endothelial growth factor-C expression. Clinics (Sao. Paulo). 67, 901-906. doi: 10.6061/clinics/2012(08)08

Zhang, J. L., Chen, G. W., Liu, Y. C., Wang, P. Y., Wang, X., Wan YL., et al. (2012a). Secreted protein acidic and rich in cysteine (SPARC) suppresses angiogenesis by down-regulating the expression of VEGF and MMP-7 in gastric cancer. PLoS ONE 7:e44618. doi: 10.1371/journal.pone.0044618

Zhang, Z., Pan, J., Li, L., Wang, Z., Xiao, W., and Li, N. (2011a). Survey of risk factors contributed to lymphatic metastasis in patients with oral tongue cancer by immunohistochemistry. J. Oral Pathol. Med. 40, 127-134. doi: 10.1111/j.16000714.2010.00953.x

Zumsteg, A., Baeriswyl, V., Imaizumi, N., Schwendener, R., Ruegg, C., and Christofori, G. (2009). Myeloid cells contribute to tumor lymphangiogenesis. PLoS ONE 4:e7067. doi: 10.1371/journal.pone.0007067

Conflict of Interest Statement: The authors declare that the research was conducted in the absence of any commercial or financial relationships that could be construed as a potential conflict of interest.

Received: 15 June 2013; accepted: 06 February 2014; published online: 05 March 2014. Citation: Riabov V, Gudima A, Wang N, Mickley A, Orekhov A and Kzhyshkowska J (2014) Role of tumor associated macrophages in tumor angiogenesis and lymphangiogenesis. Front. Physiol. 5:75. doi: 10.3389/fphys.2014.00075

This article was submitted to Vascular Physiology, a section of the journal Frontiers in Physiology.

Copyright (c) 2014 Riabov, Gudima, Wang, Mickley, Orekhov and Kzhyshkowska. This is an open-access article distributed under the terms of the Creative Commons Attribution License (CC BY). The use, distribution or reproduction in other forums is permitted, provided the original author(s) or licensor are credited and that the original publication in this journal is cited, in accordance with accepted academic practice. No use, distribution or reproduction is permitted which does not comply with these terms. 